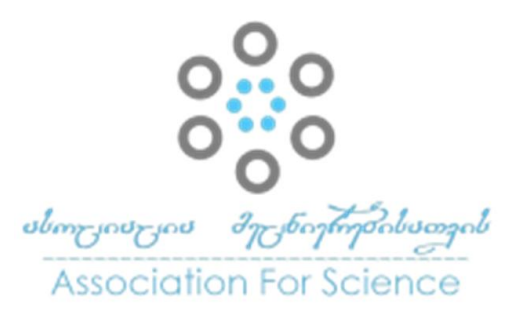

Georgian Scientists

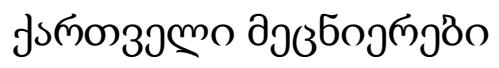

Vol. 3 I ssue 3, 2021

https://doi.org/10.52340/gs.2021.08.04

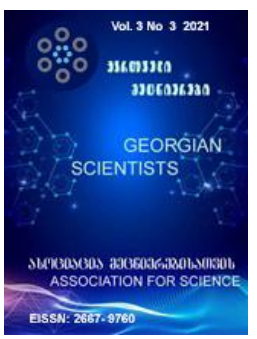

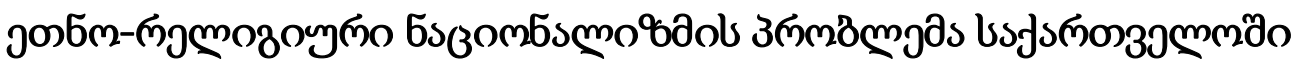

\section{on6sono6 ds3onsmsdo}

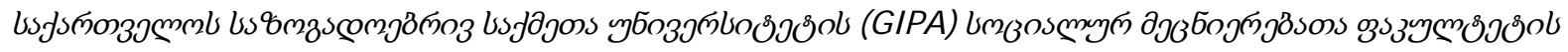

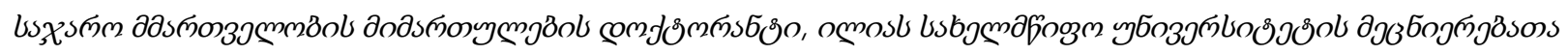

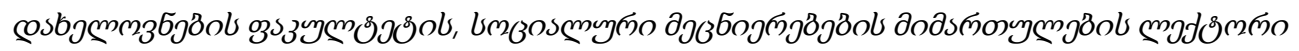

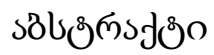

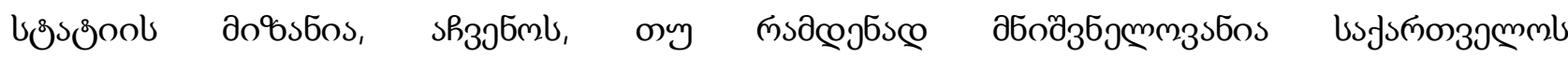

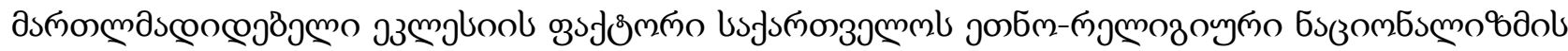

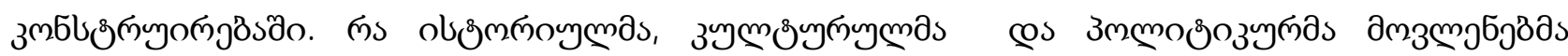

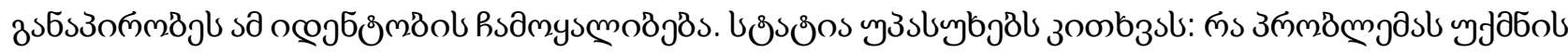

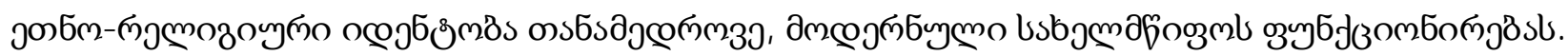

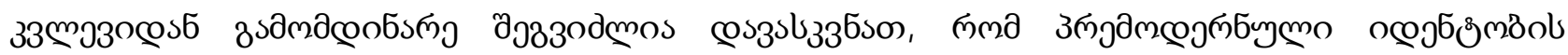

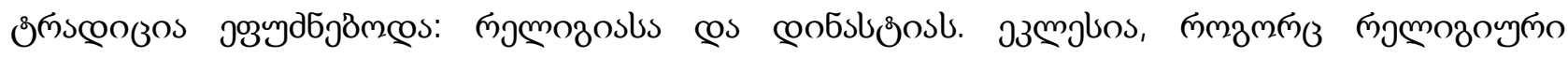

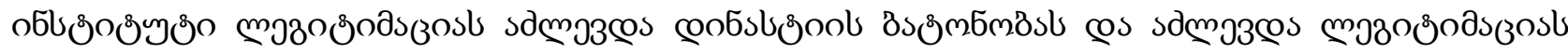

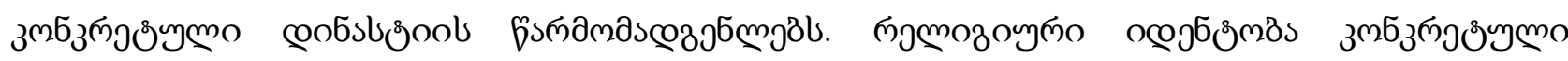

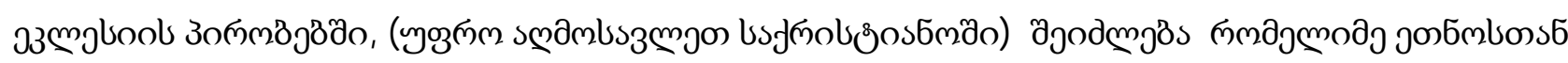

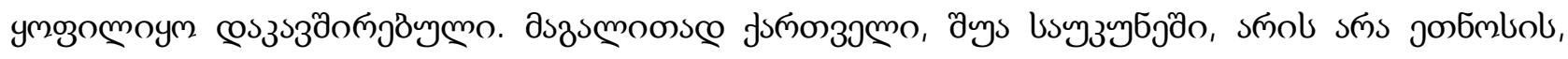

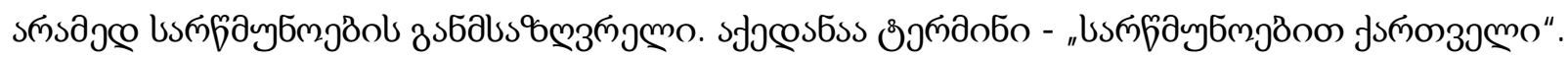

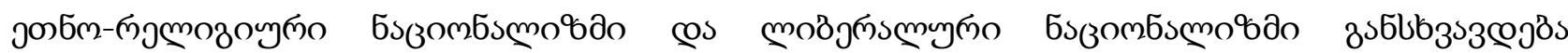

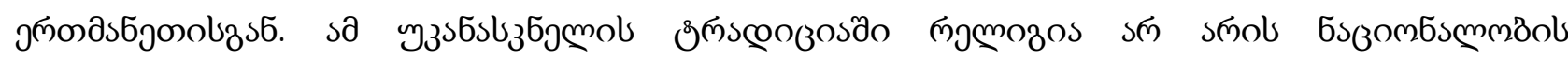

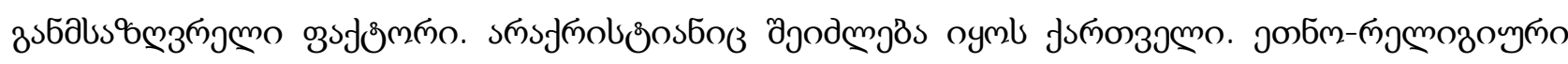

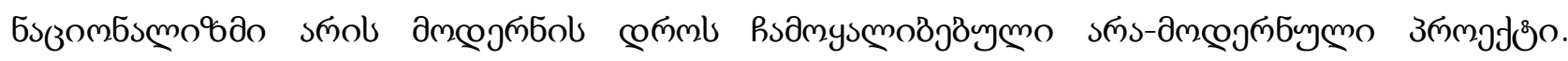

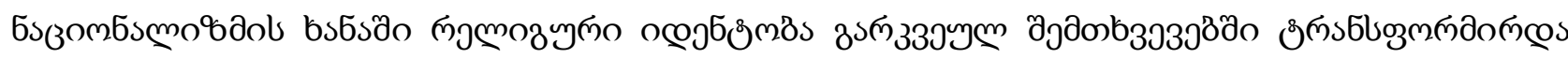

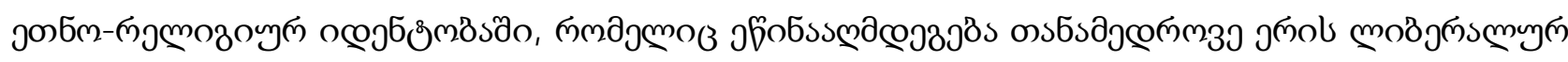

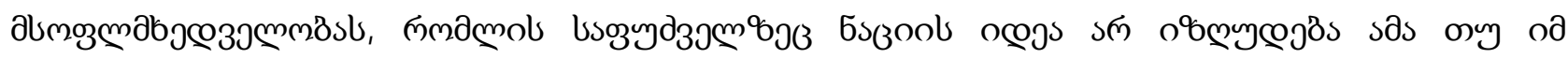

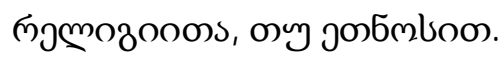

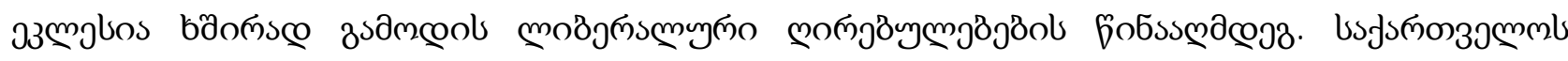

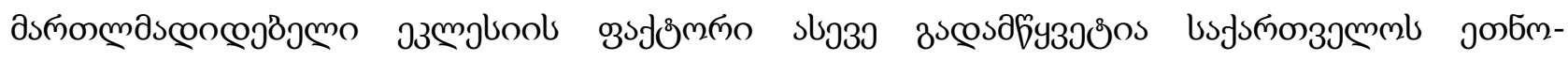




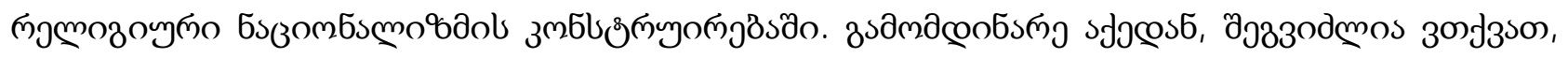

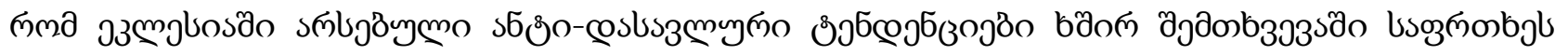

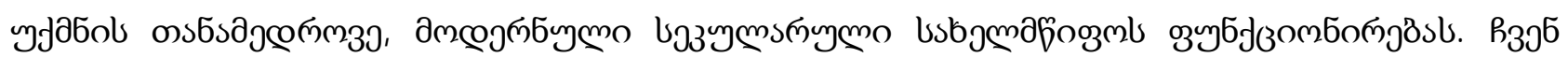

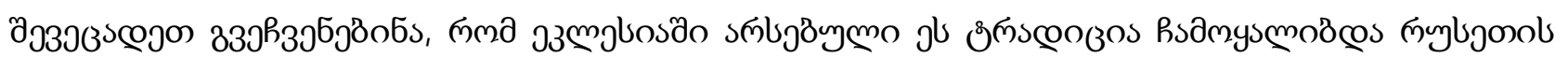

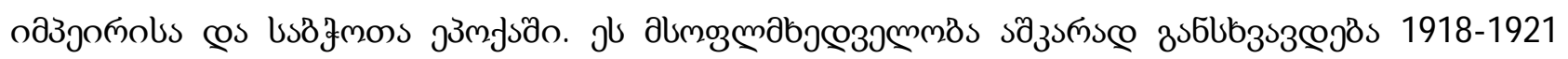

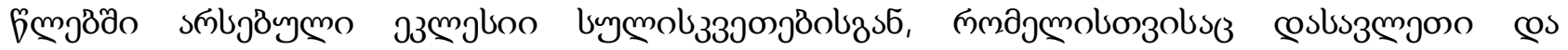

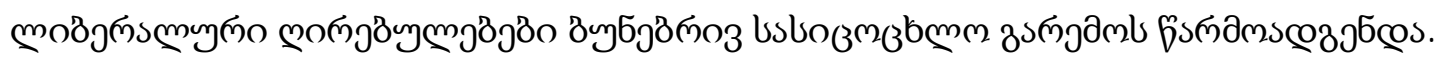

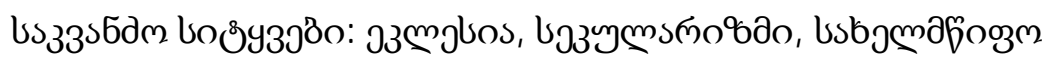




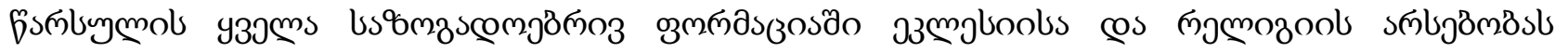

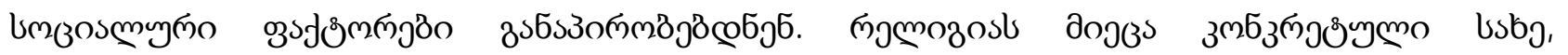

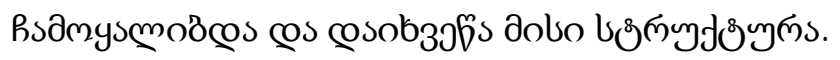

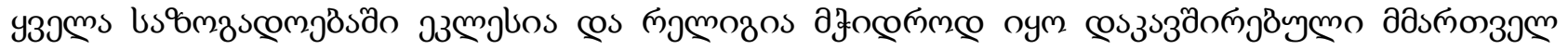

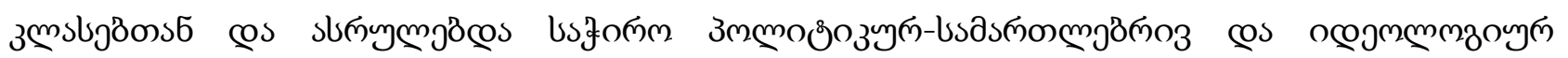

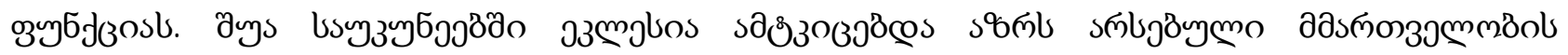

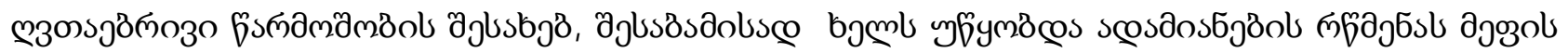

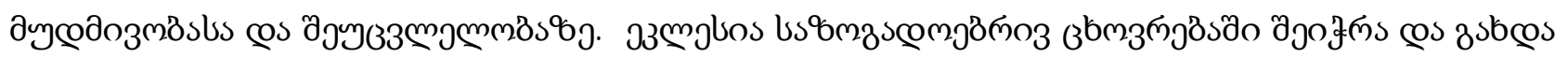

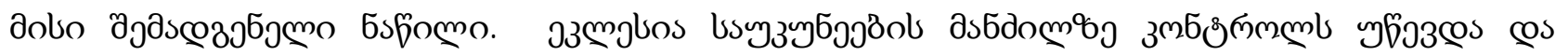

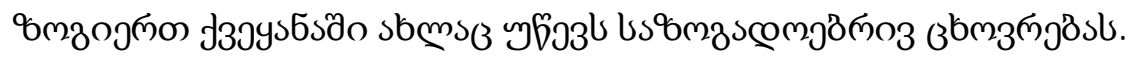

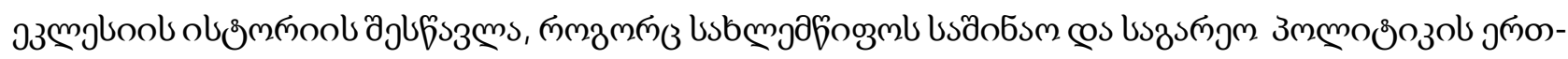

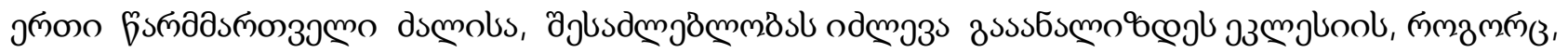

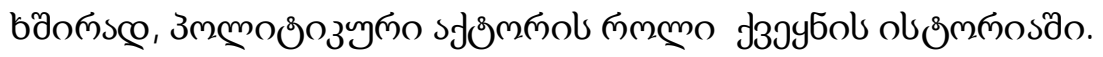

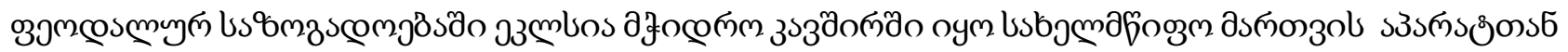

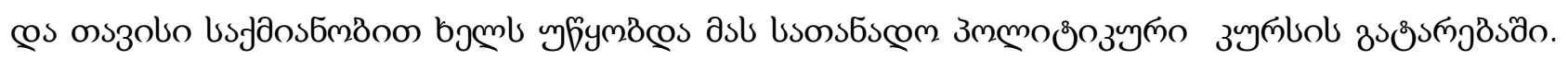

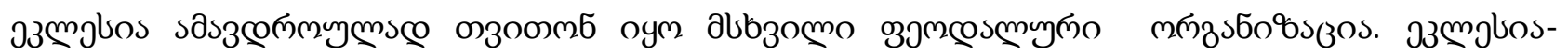

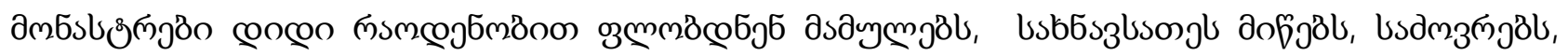

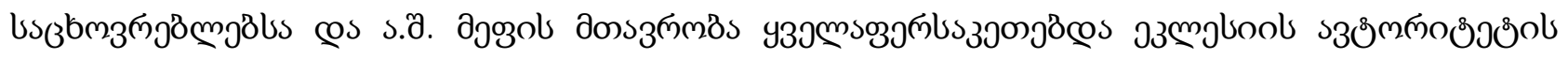

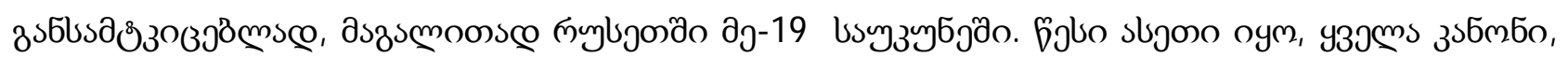

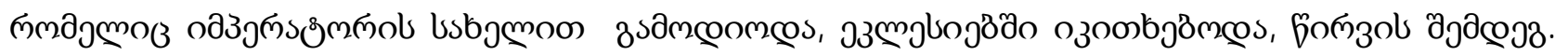

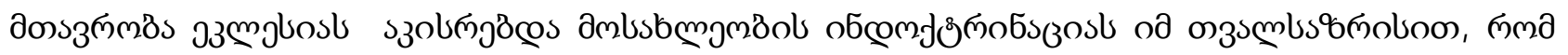

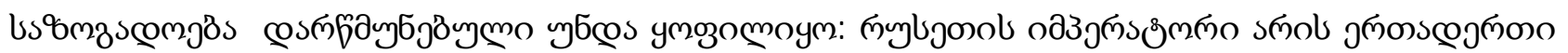

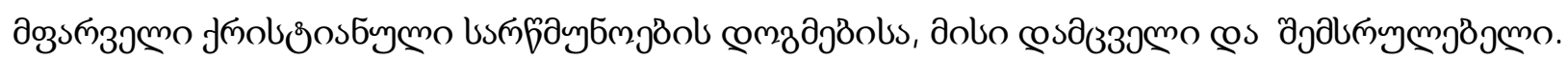

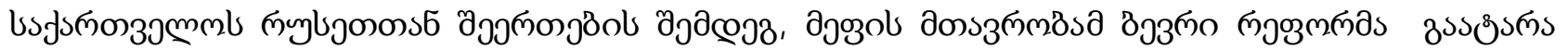

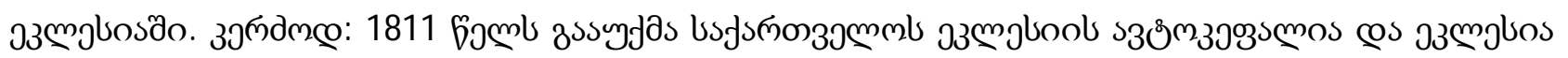

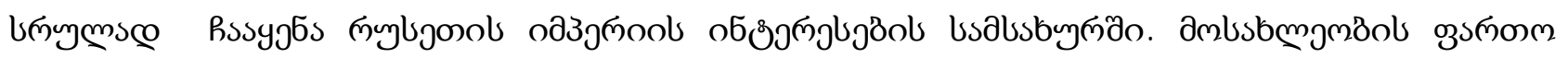

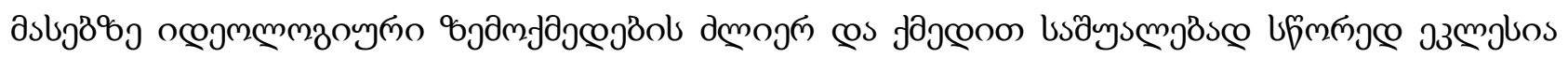

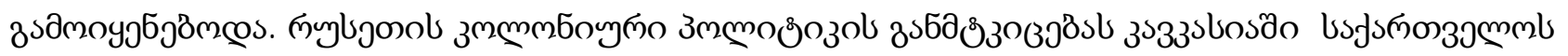

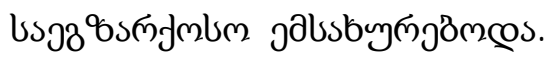

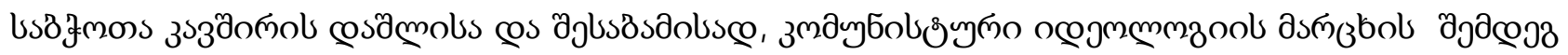

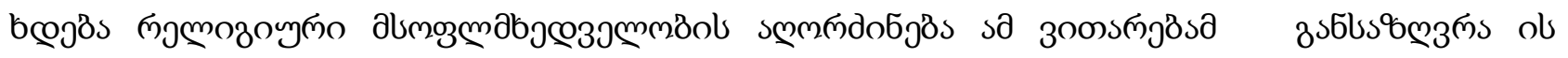

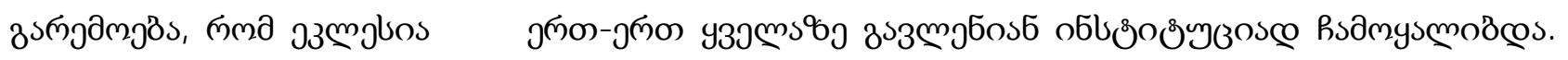

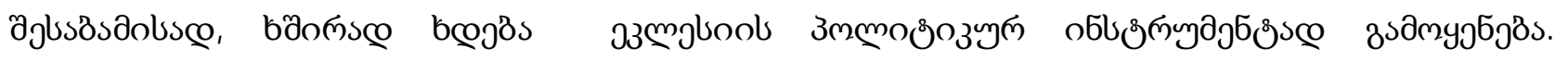

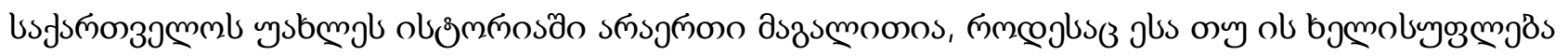




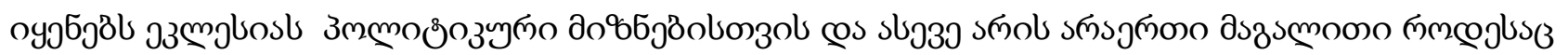

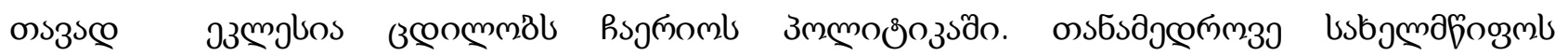

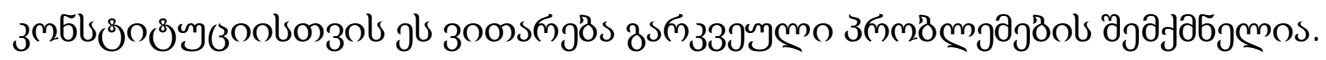

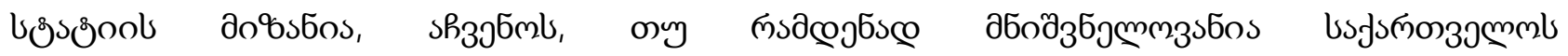

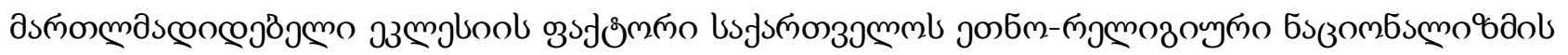

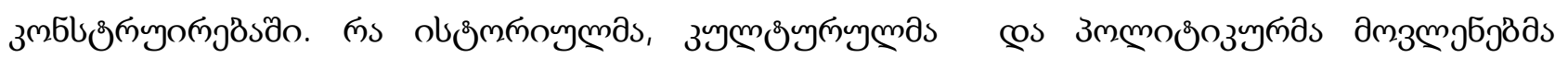

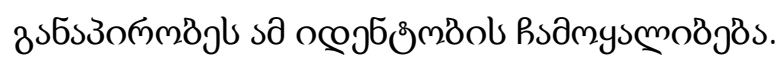

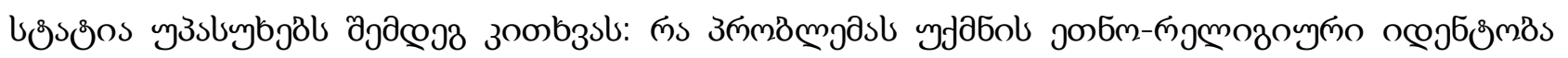

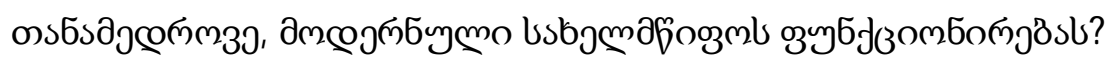

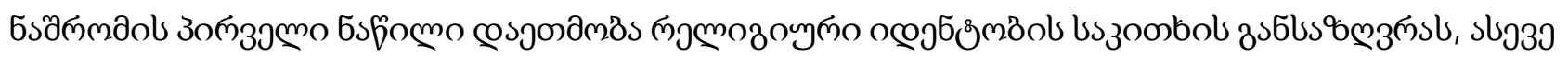

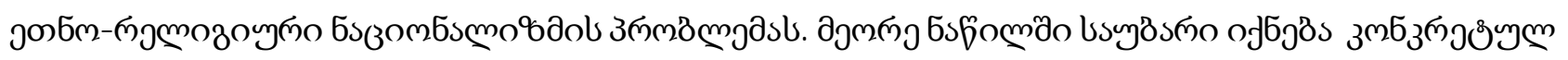

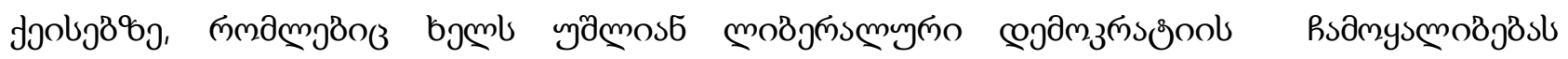

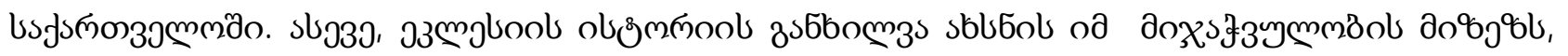

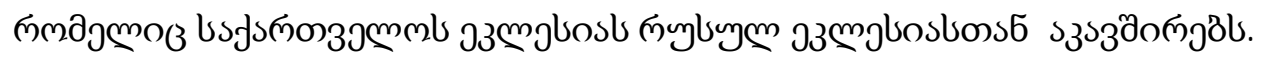

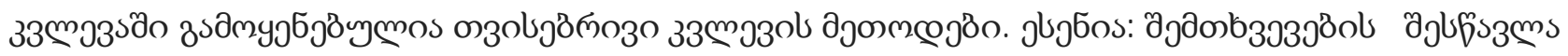

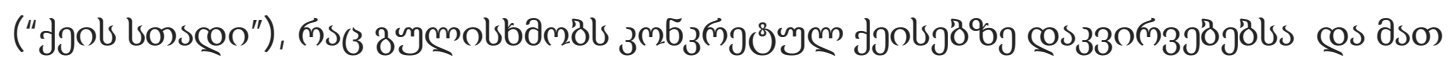

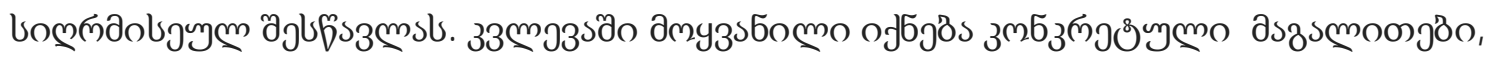

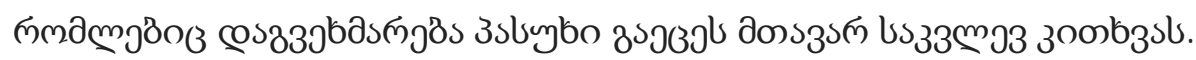

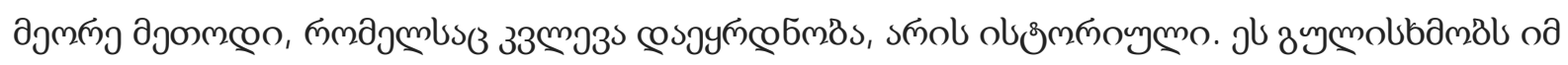

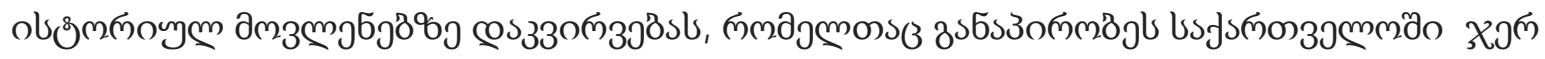

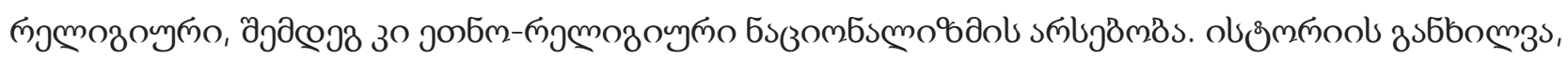

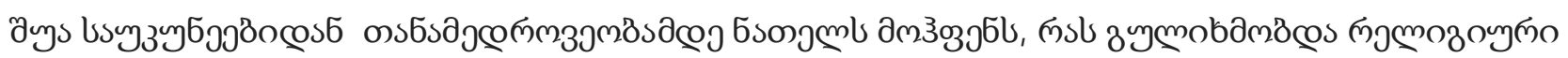

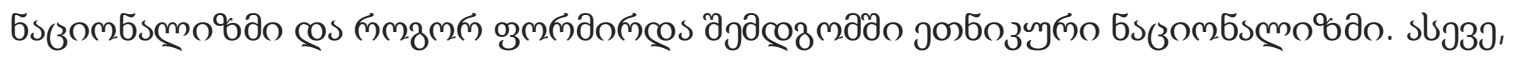
дбодзб блммз

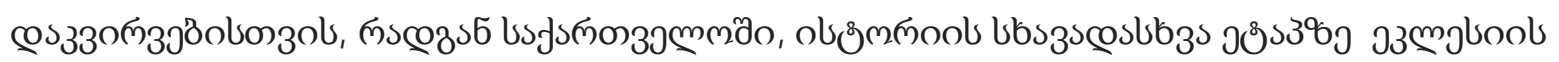

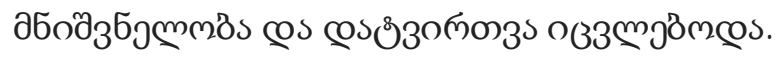

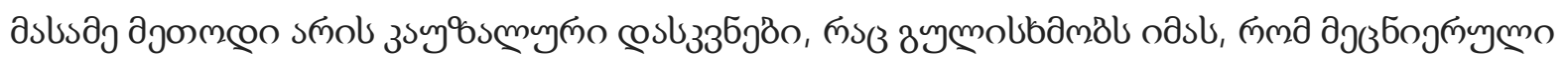

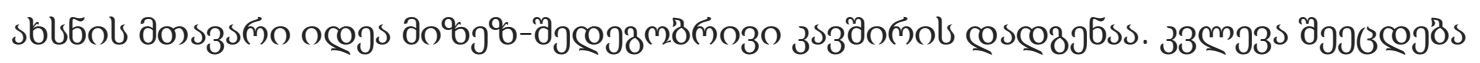

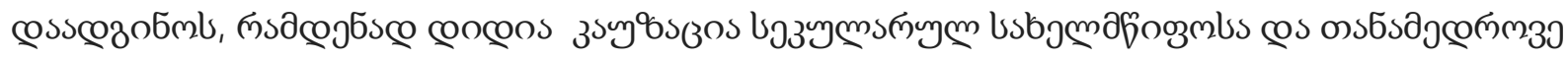

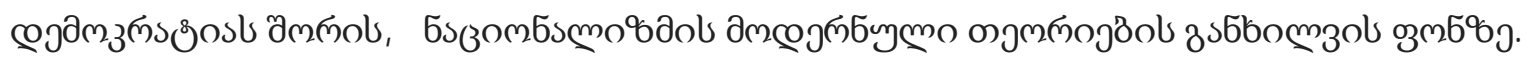

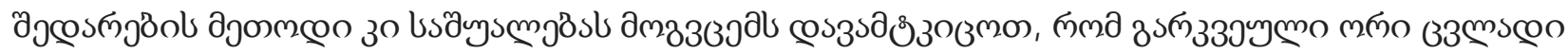

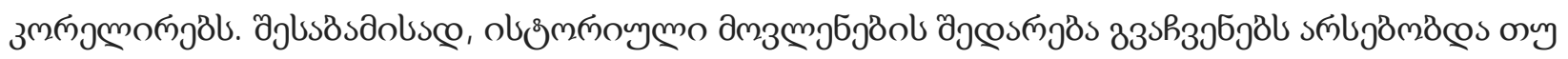

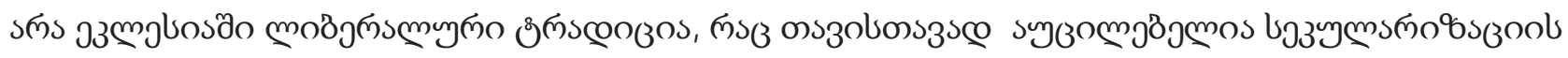

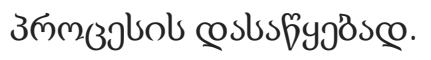




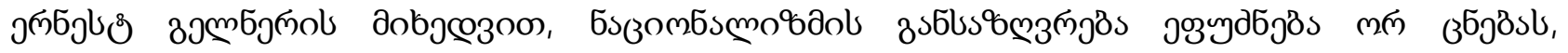

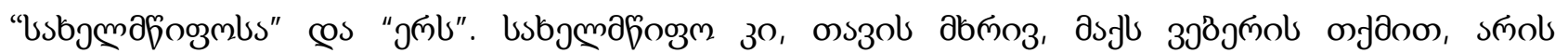

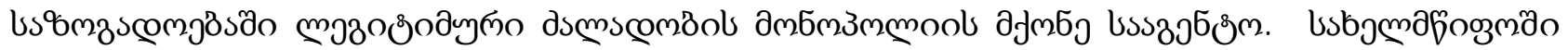

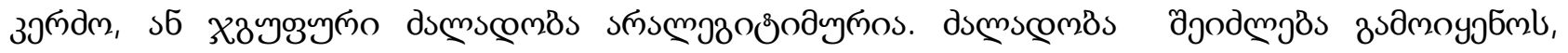

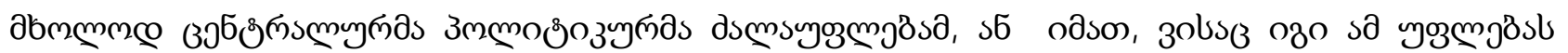

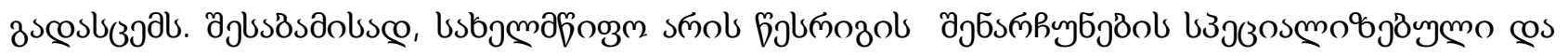

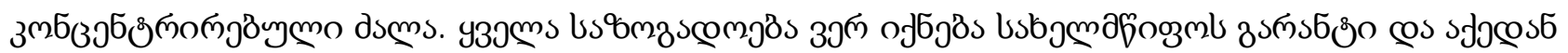

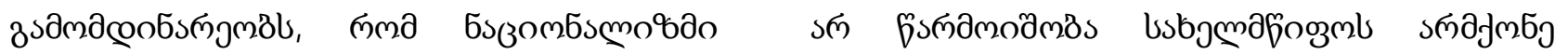

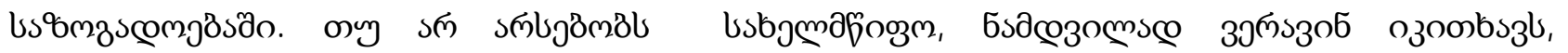

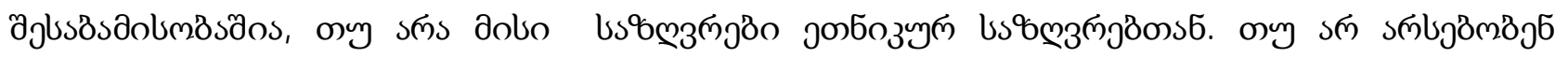

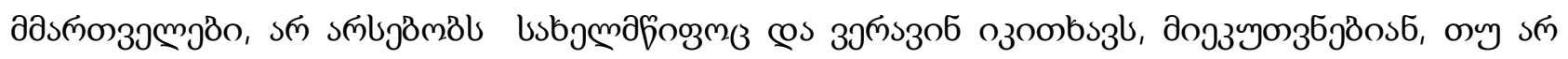

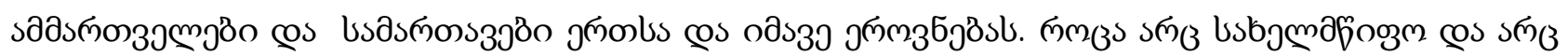

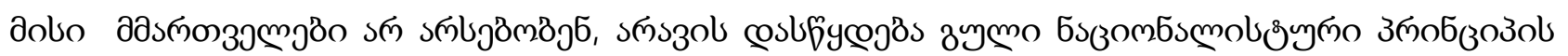

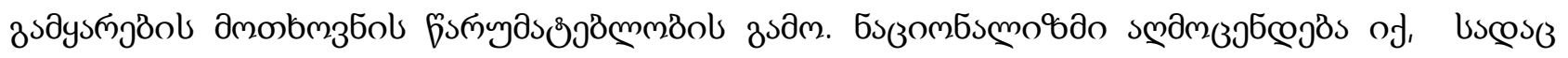

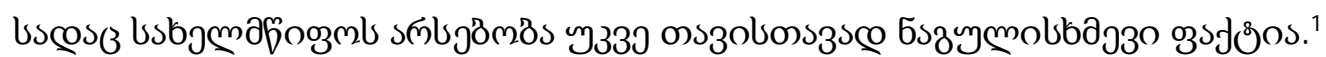

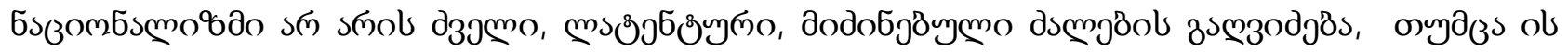

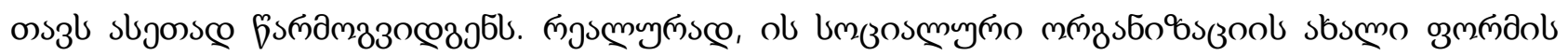

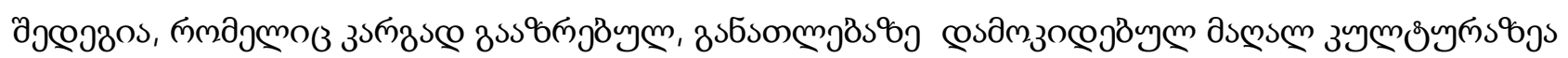

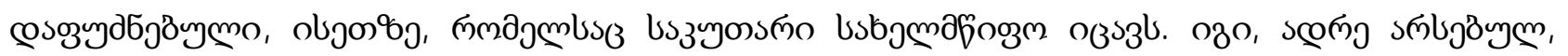

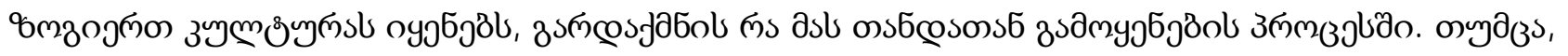

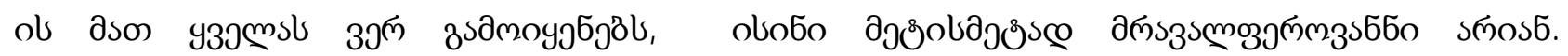

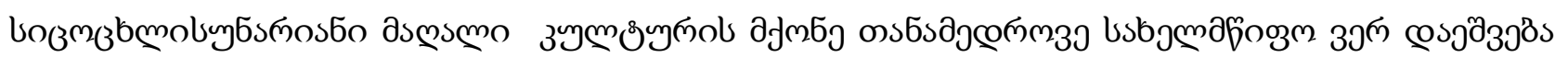

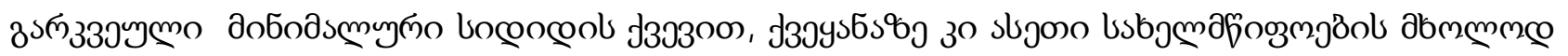

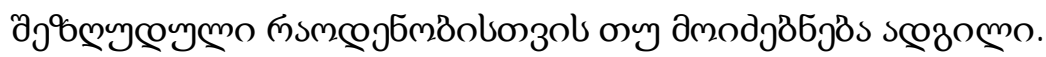

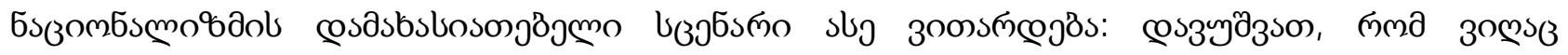

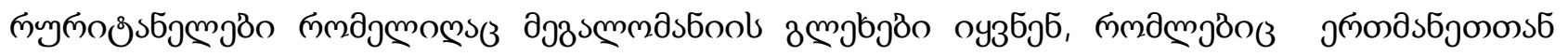

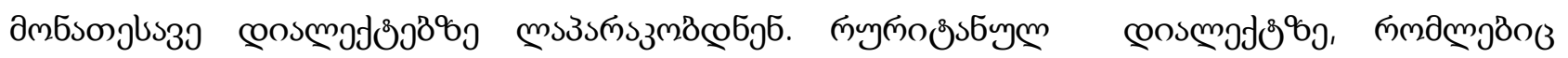

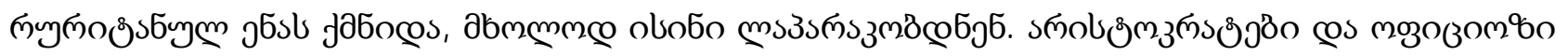

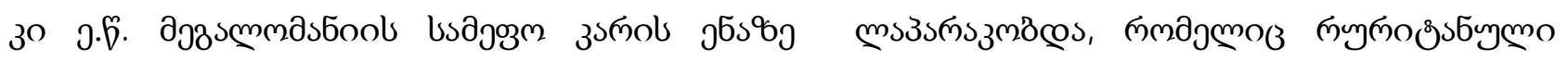

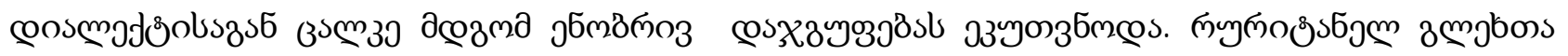

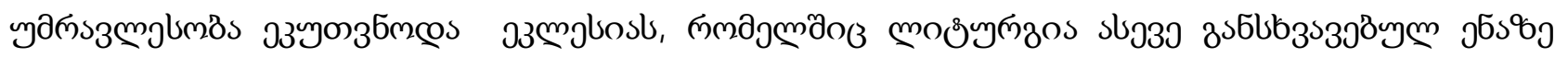

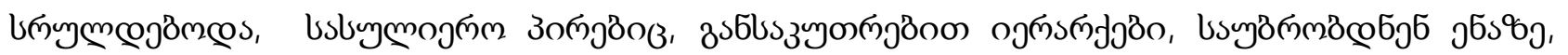

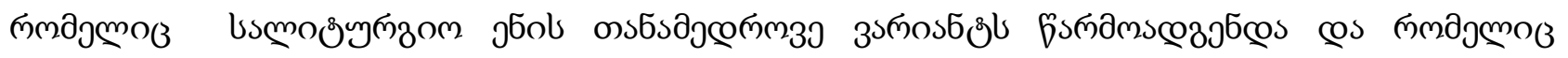

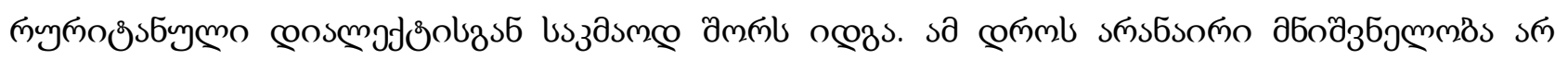

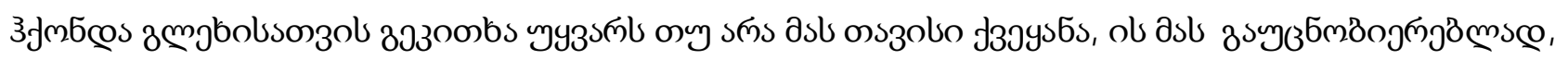

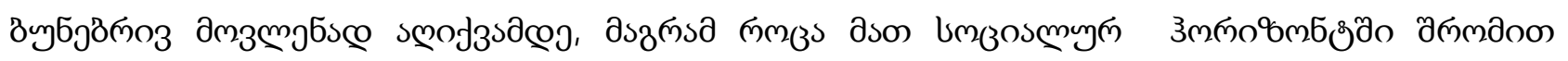

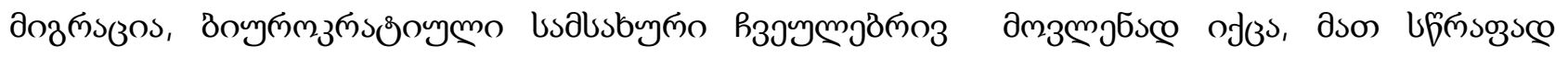




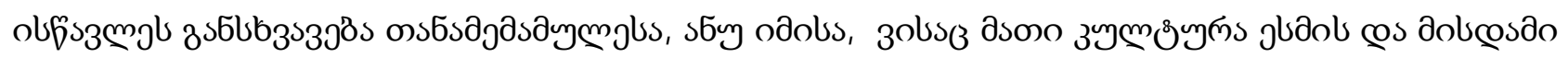

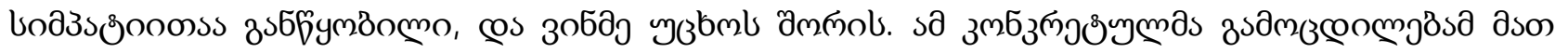

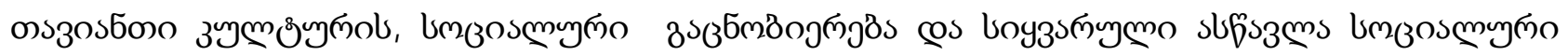

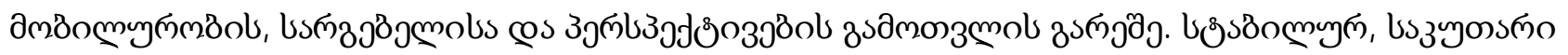

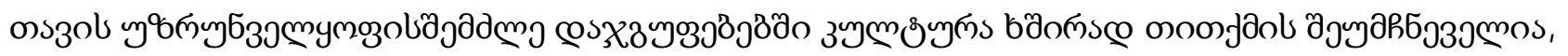

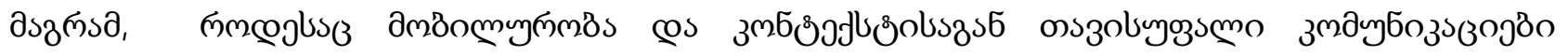

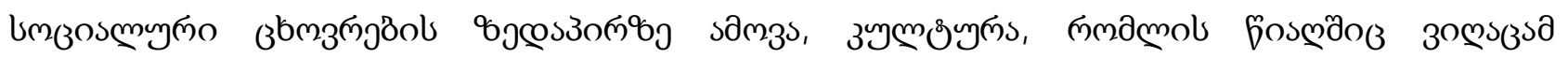

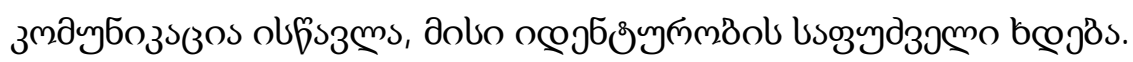

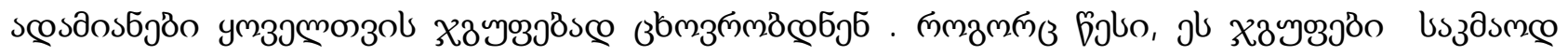

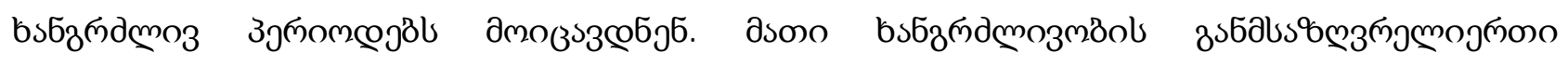

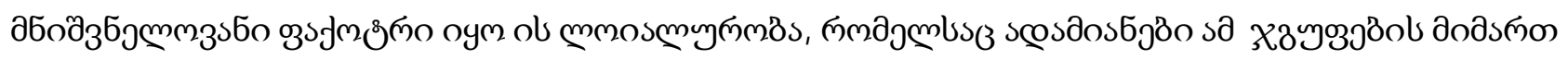

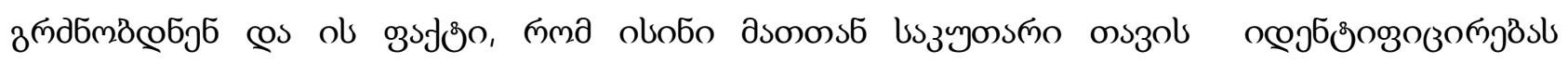

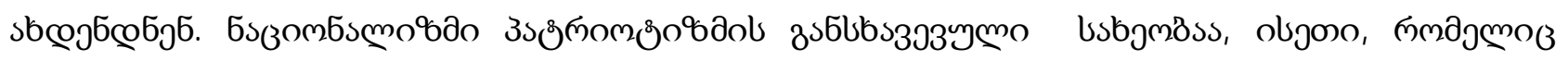

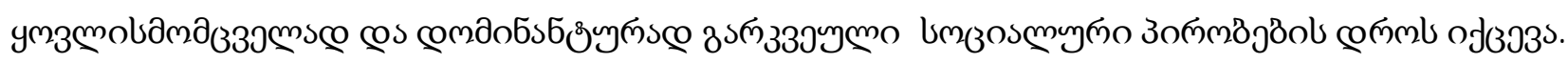

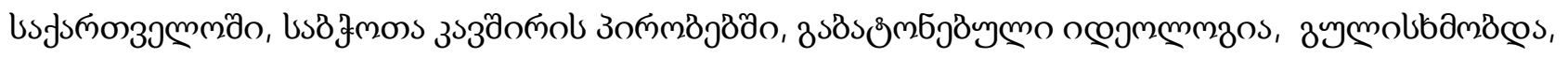

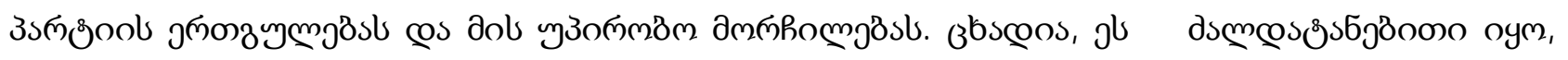

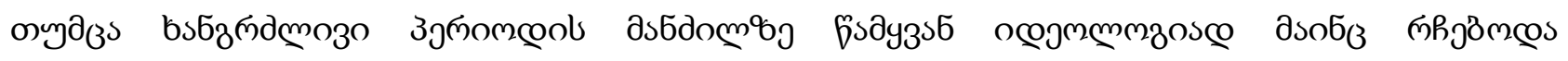

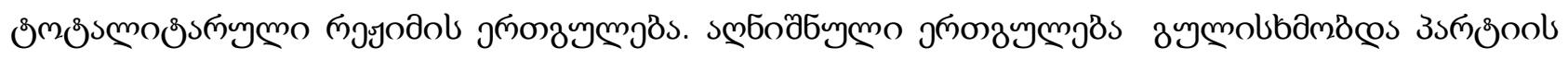

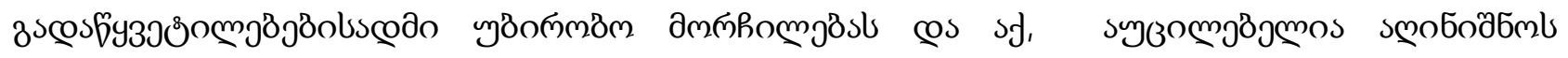

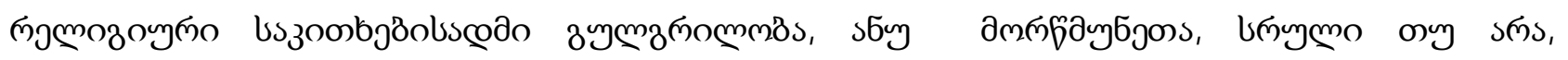

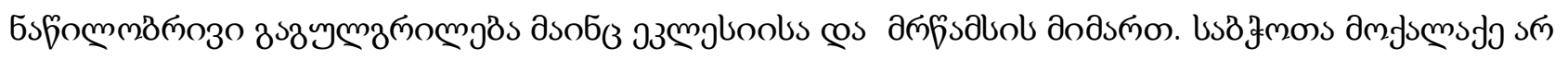

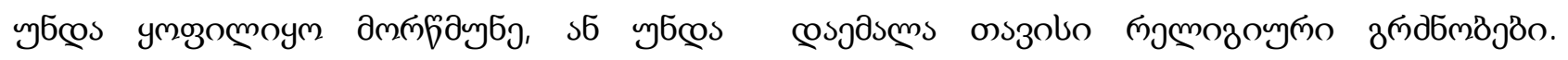

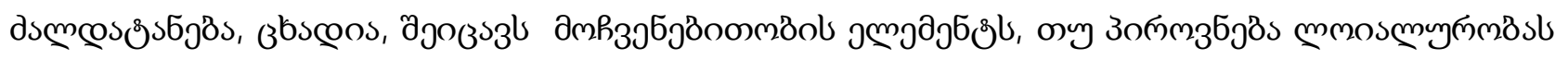

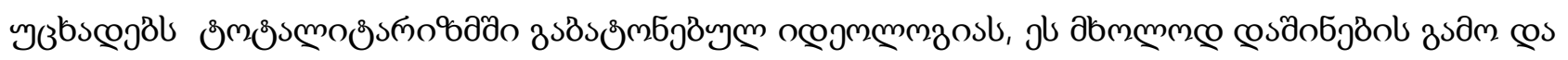

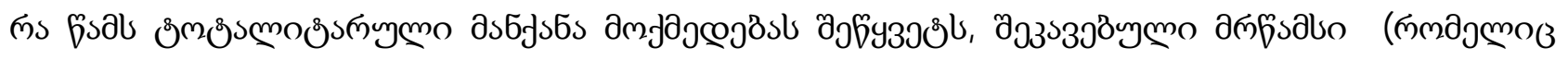

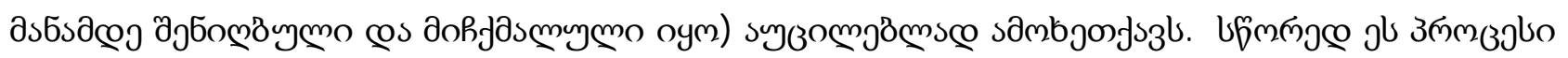

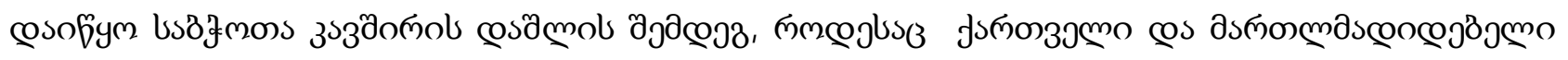

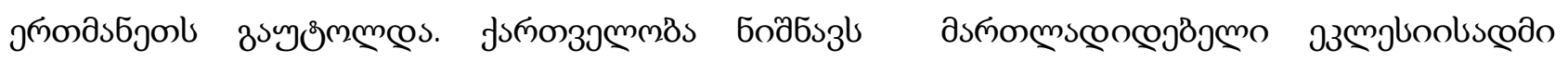

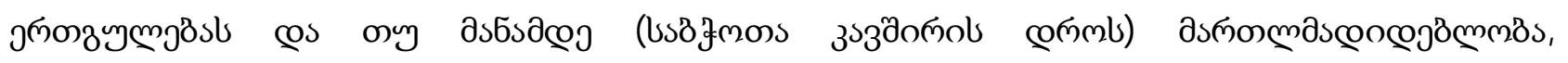

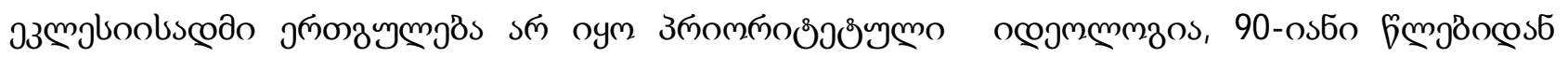

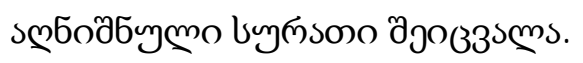

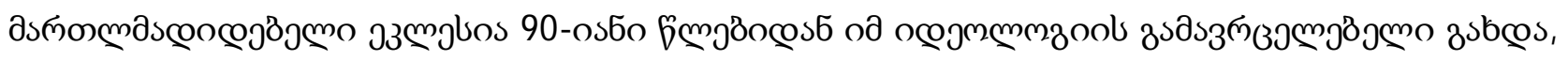

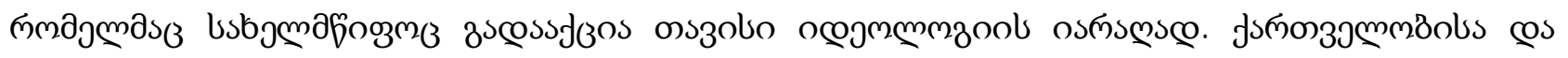

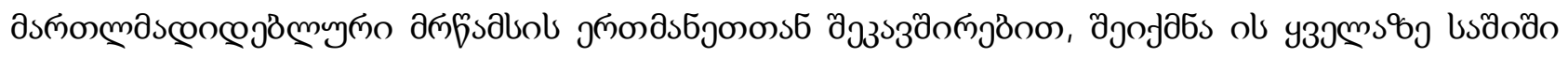

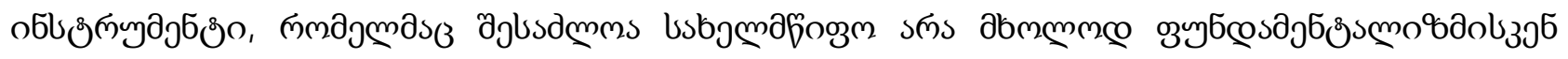

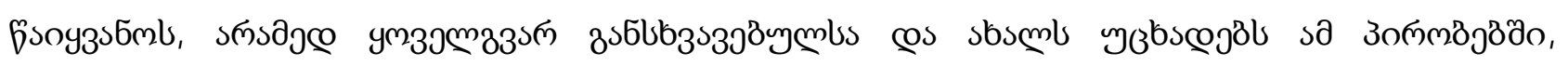

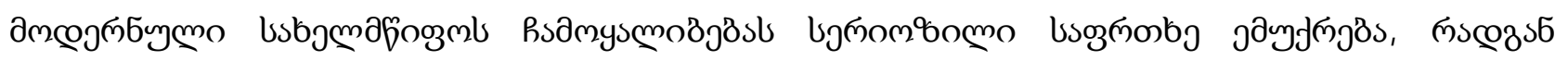




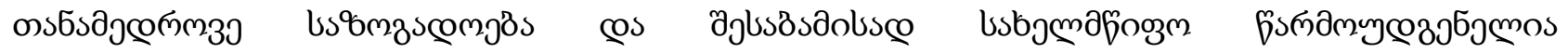

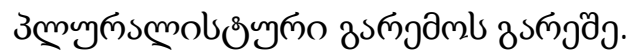

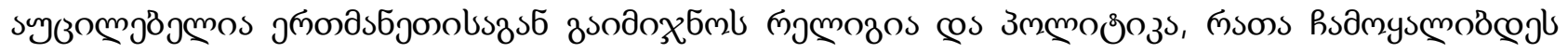

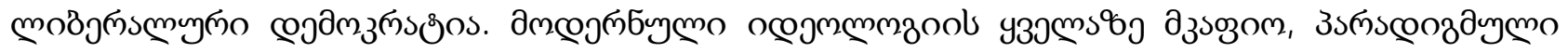

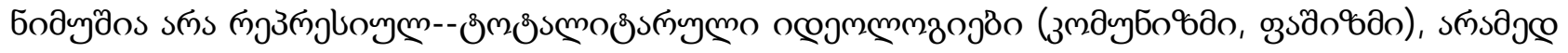

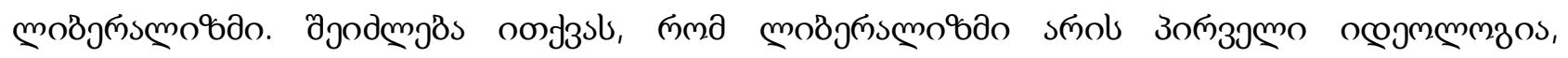

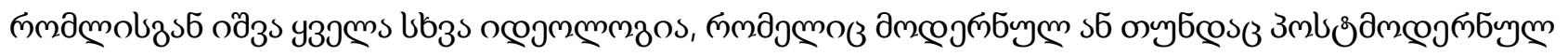

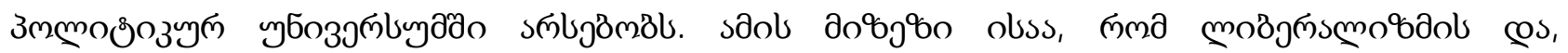

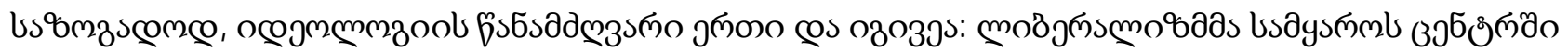

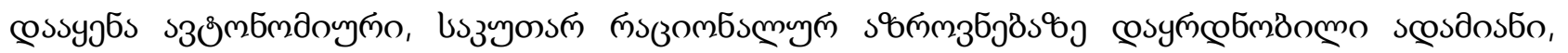

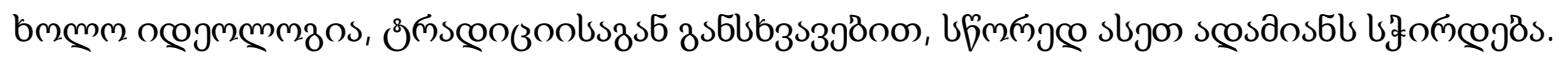

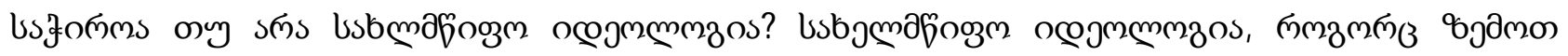

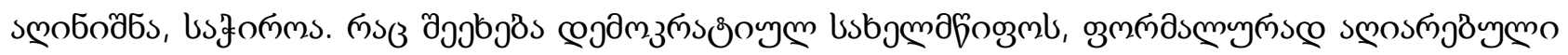

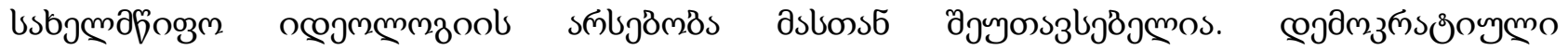

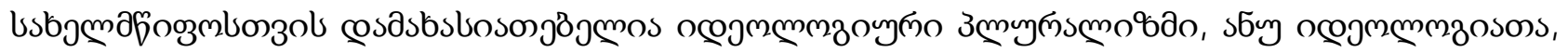

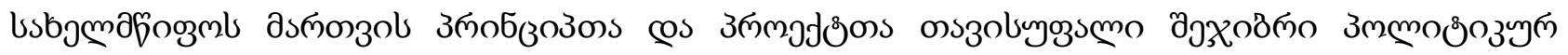

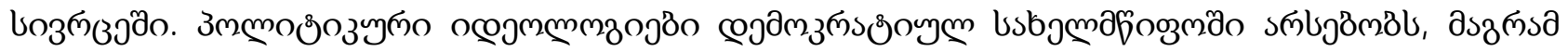

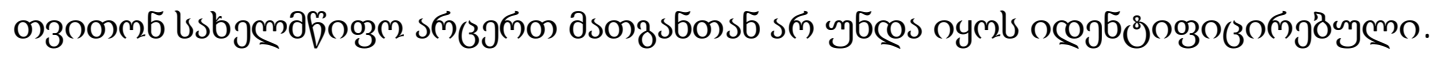

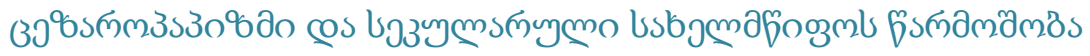

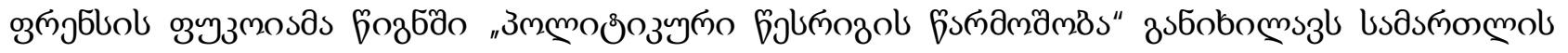
э

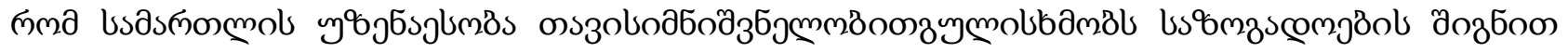

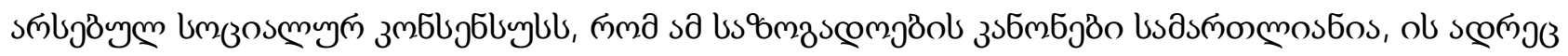

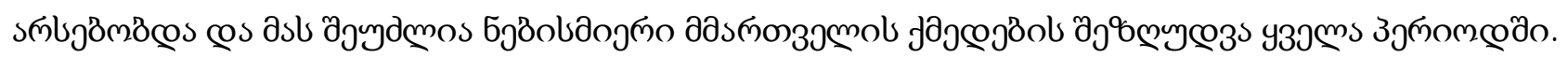

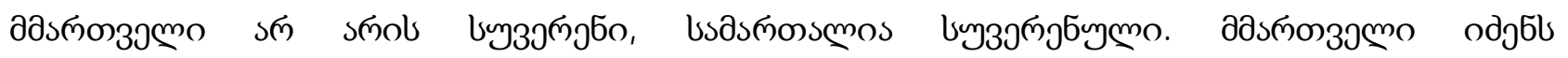

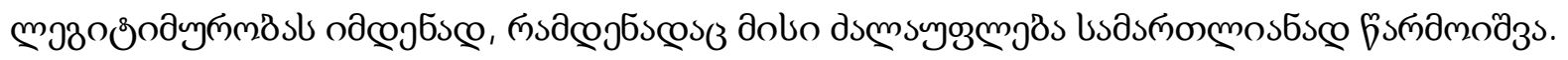

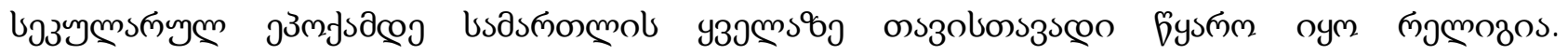

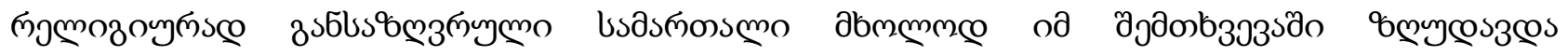

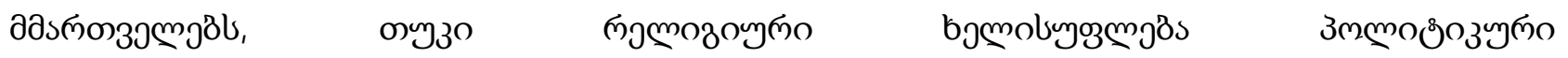

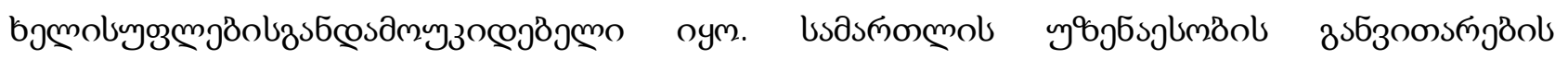

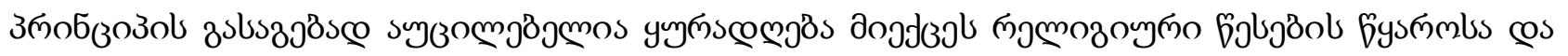

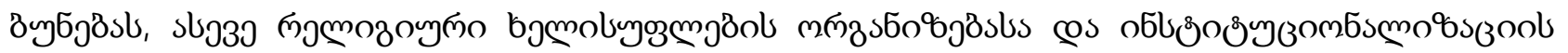

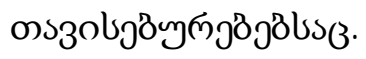

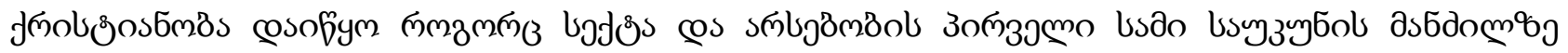

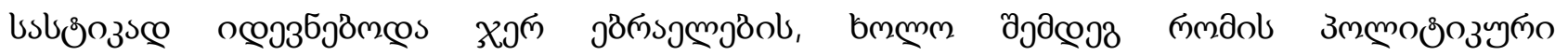




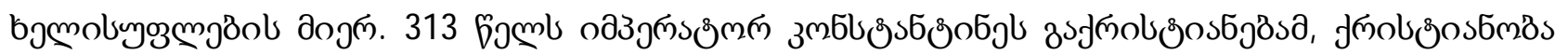

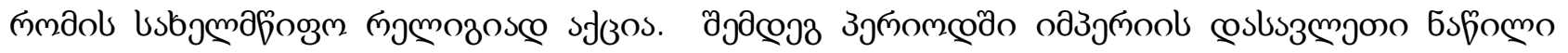

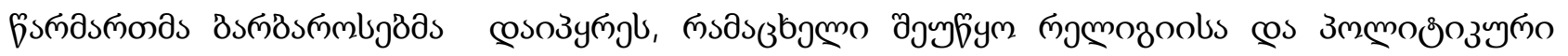

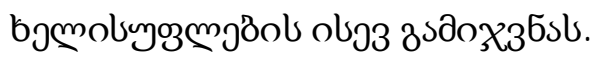

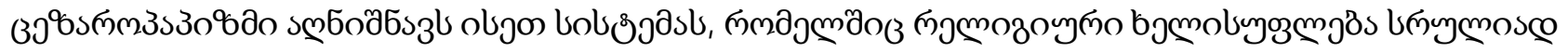

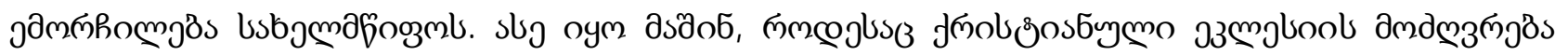

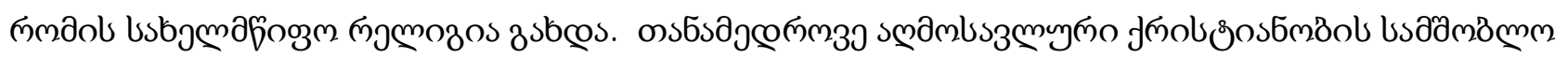

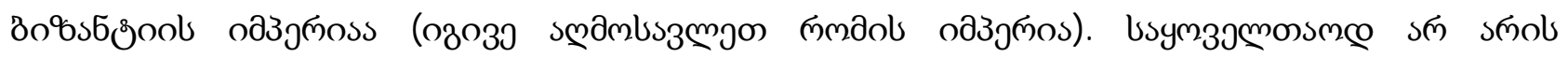

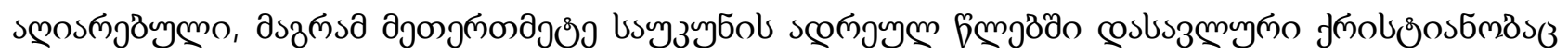

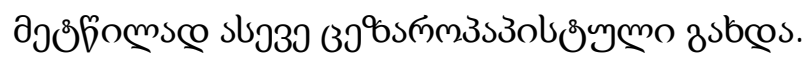

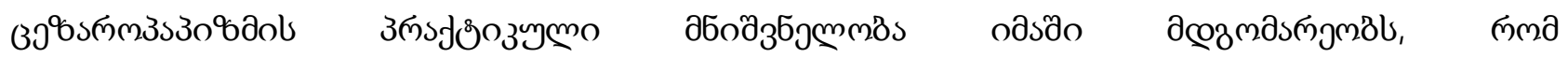

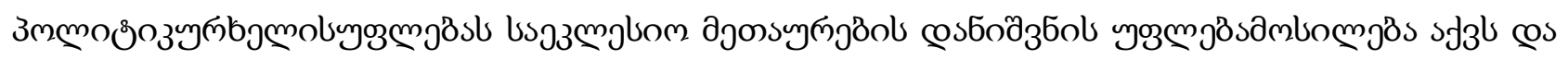

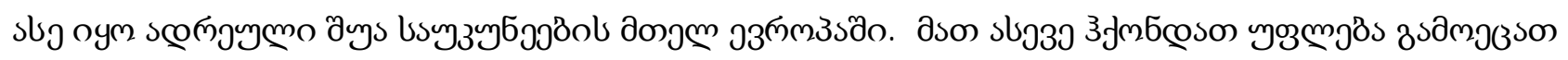

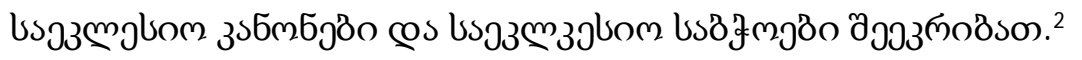

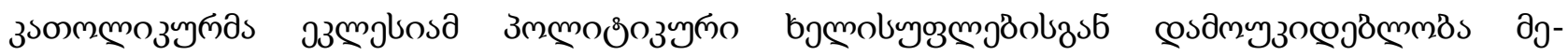

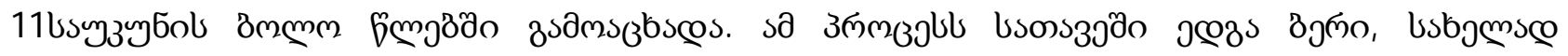

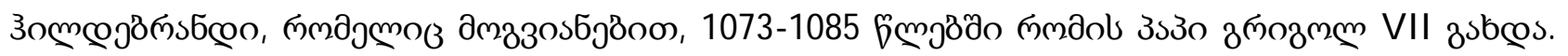

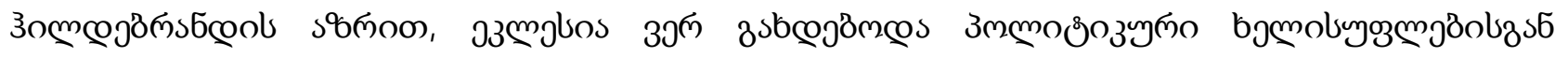

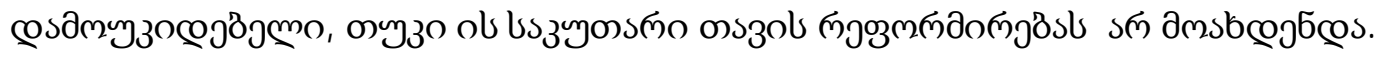

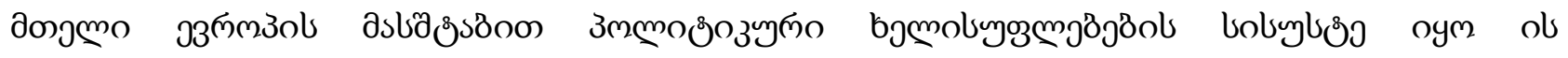

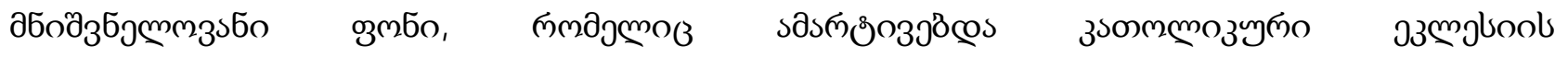

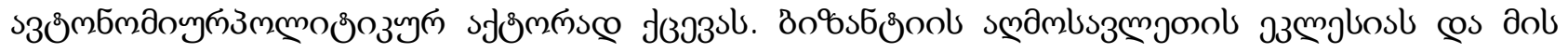

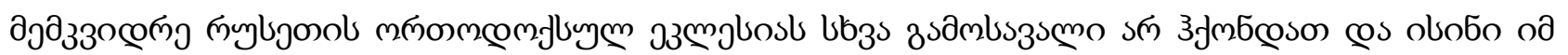

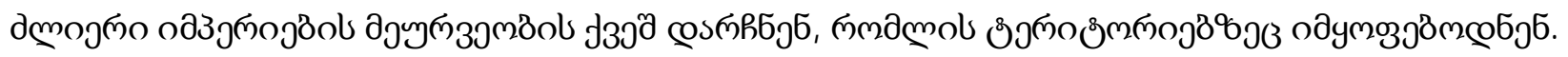

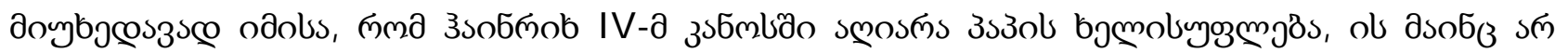

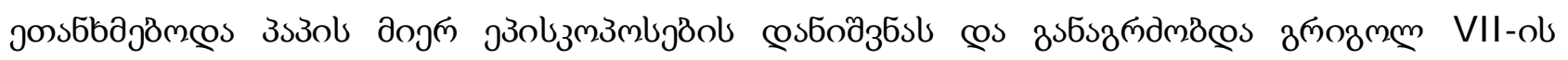

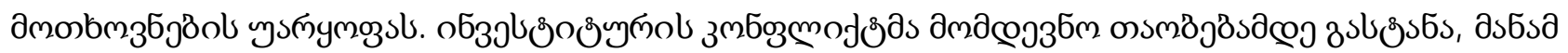

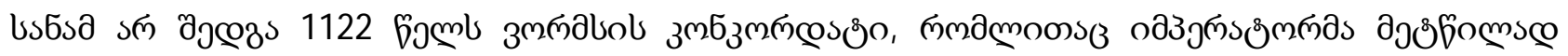

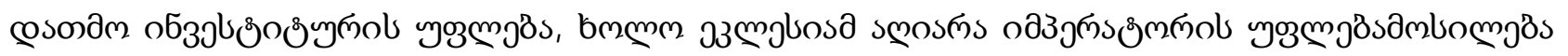

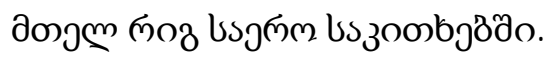

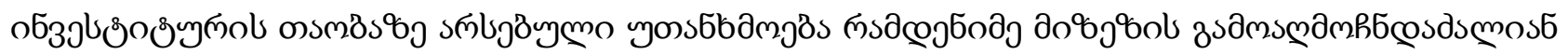

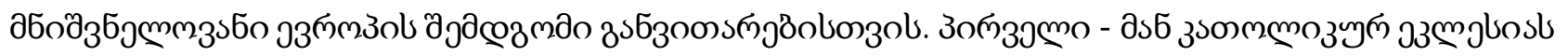

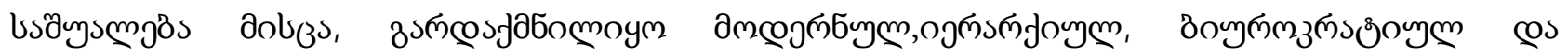

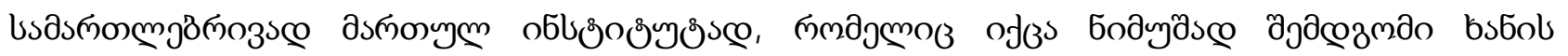

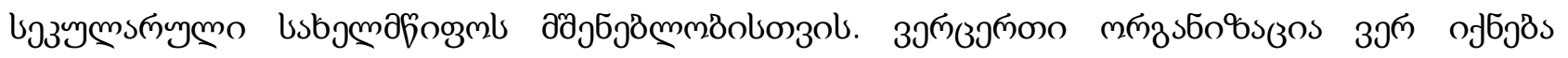

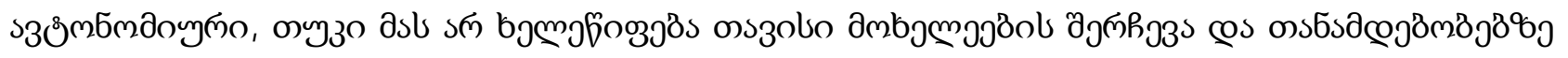

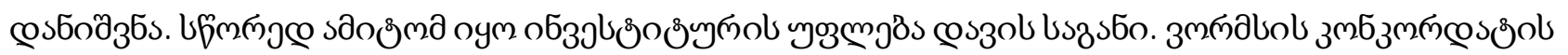




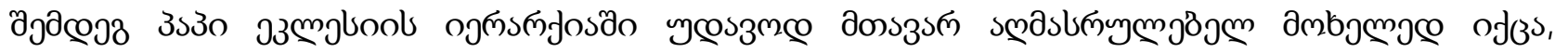

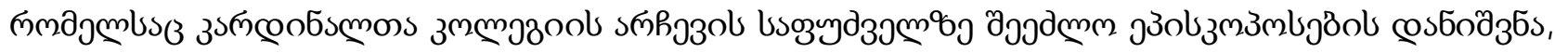
sб cososbmzбs.

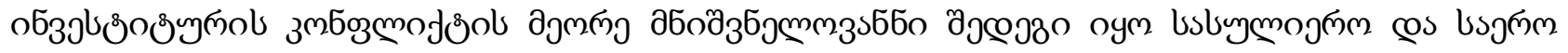

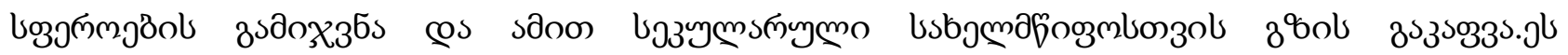

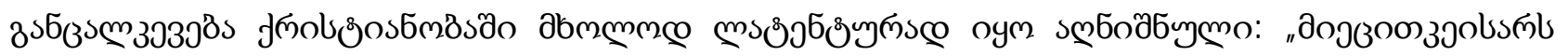

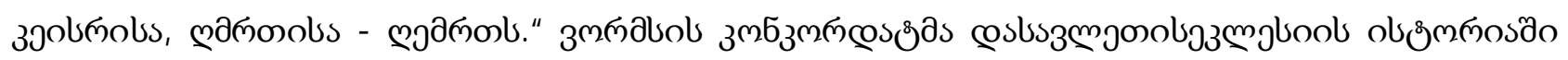

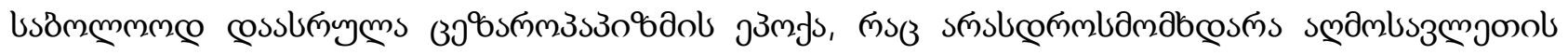

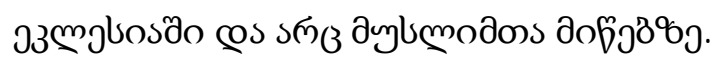

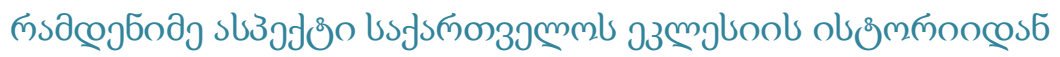

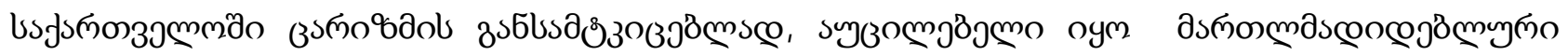

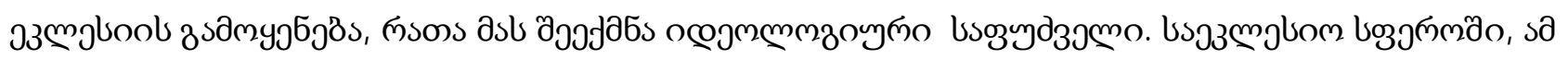

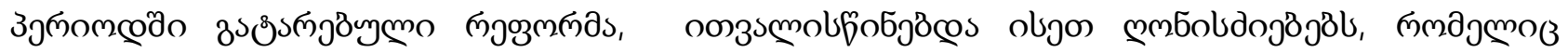

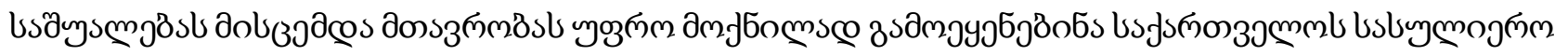

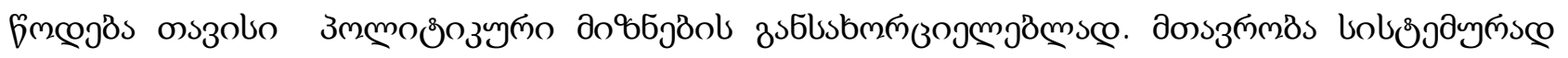

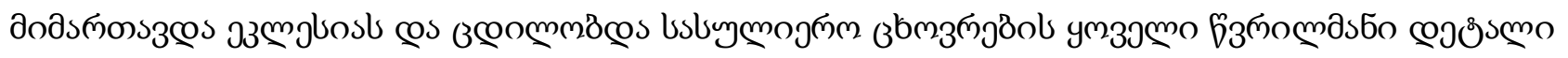

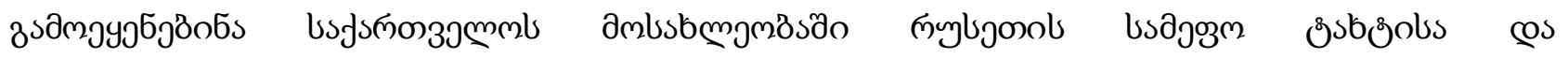

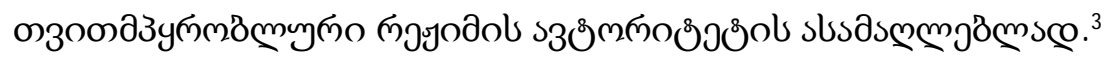

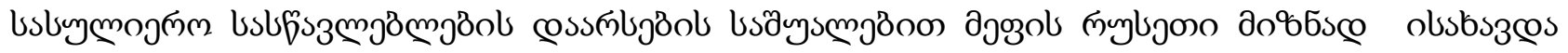

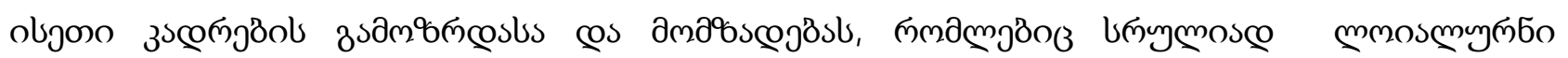

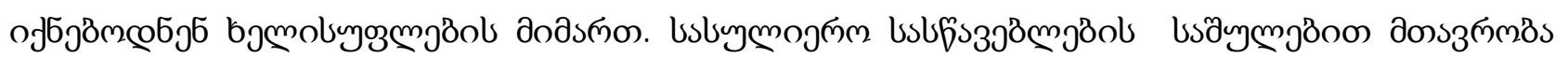

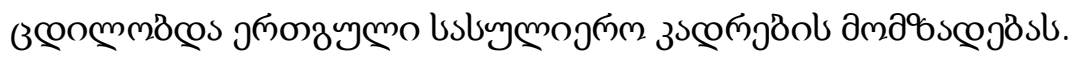

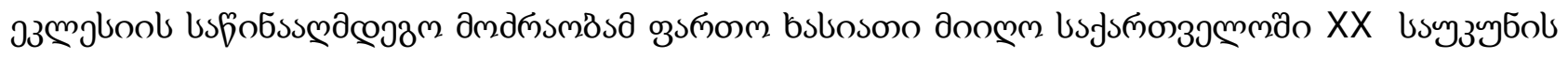

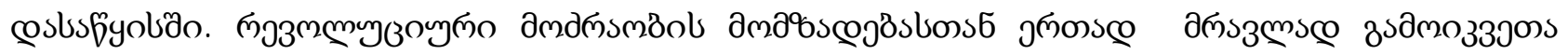

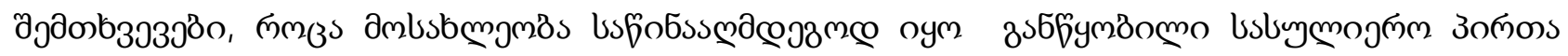

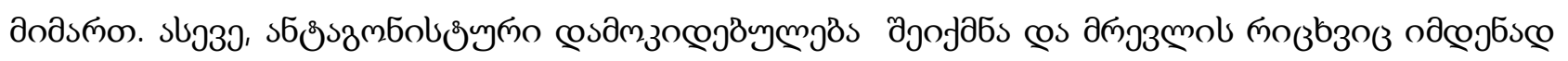

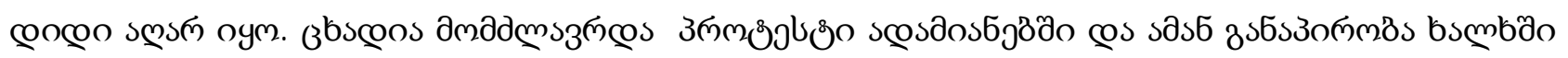

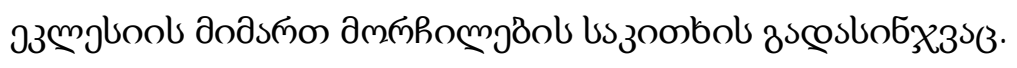

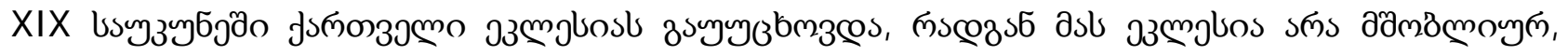

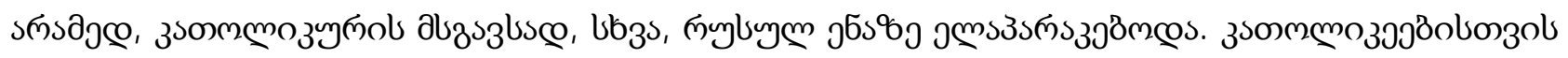

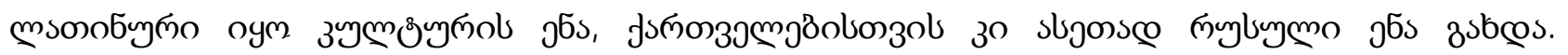

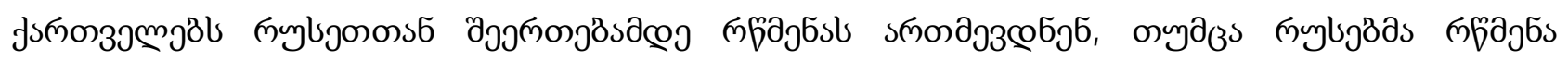

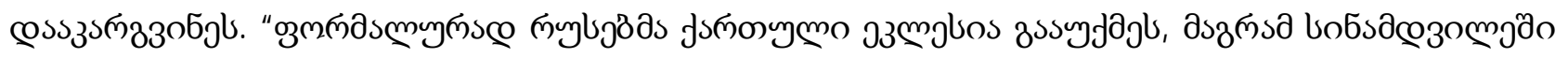

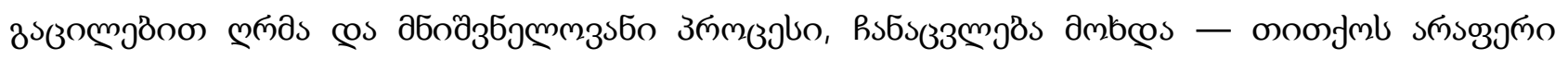

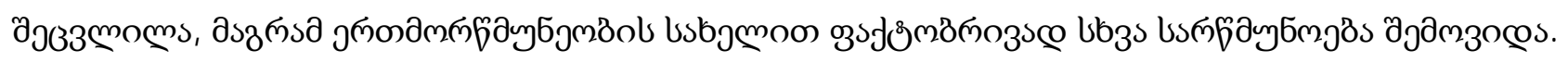




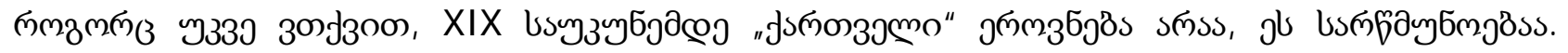

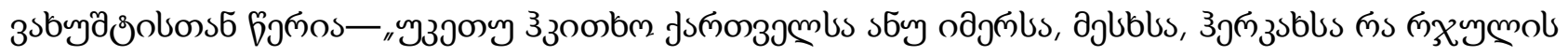

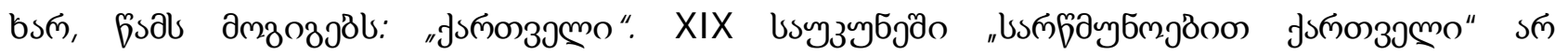

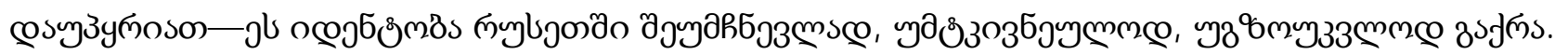

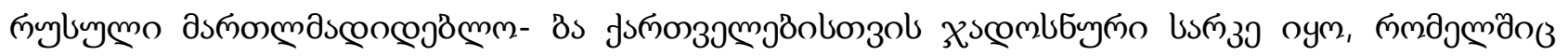
Rsob- œ

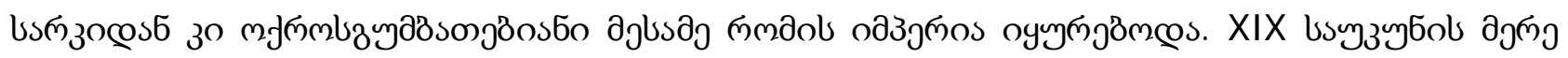

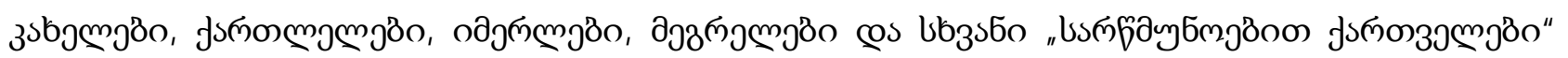

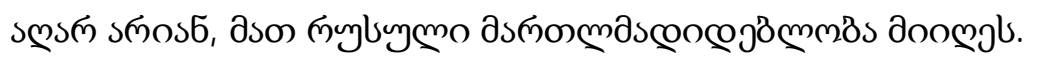

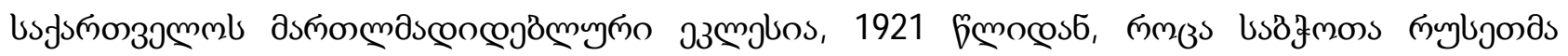

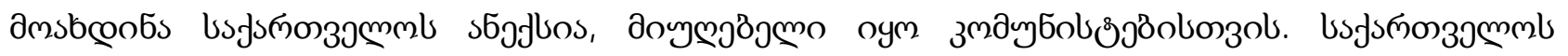

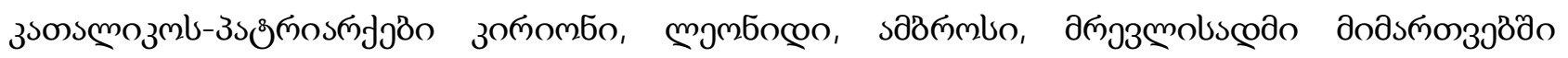

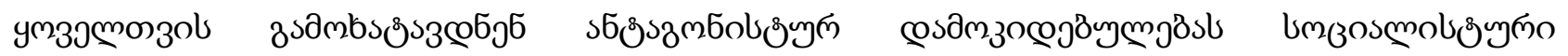

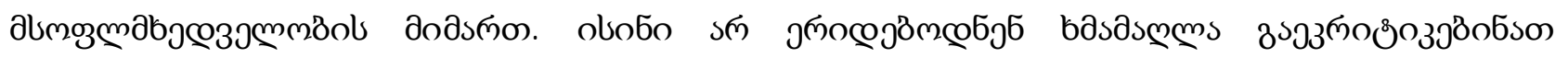

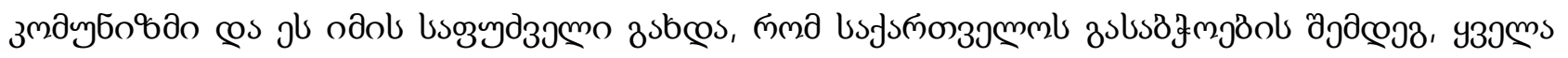

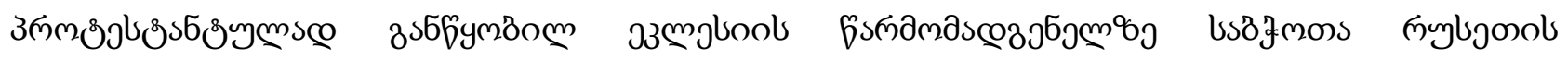

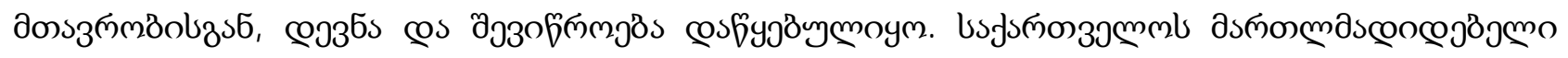

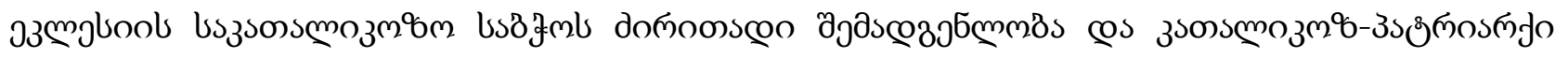

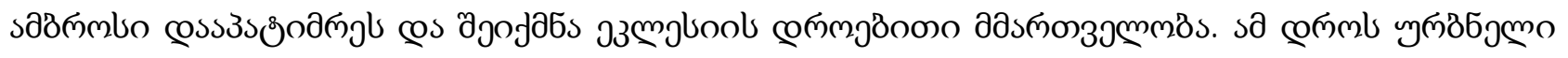

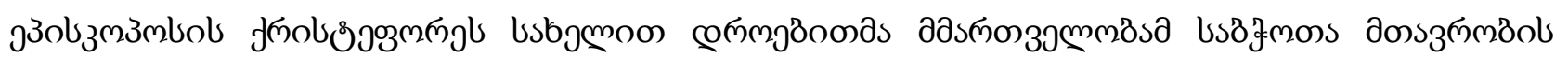

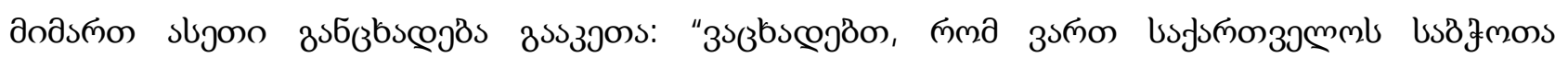

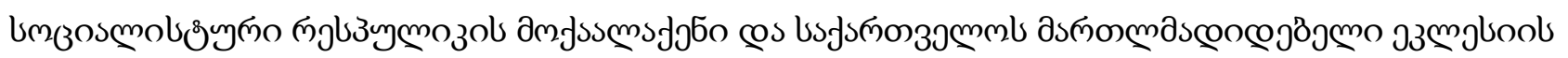

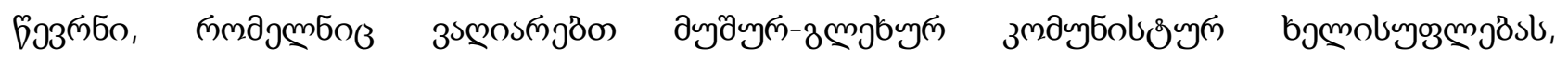

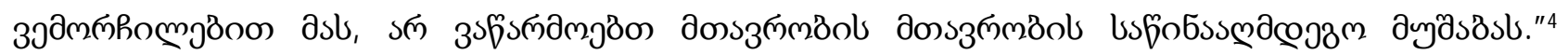

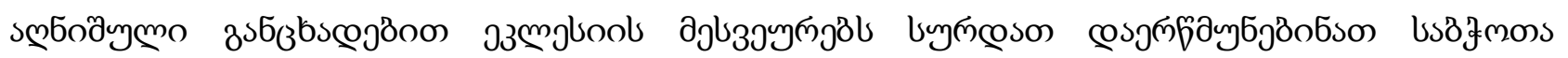

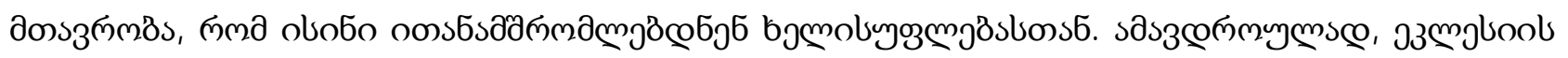

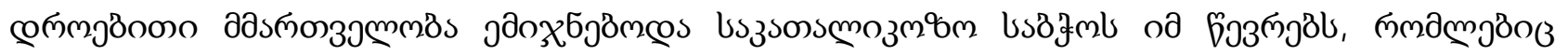

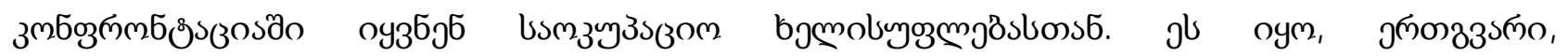

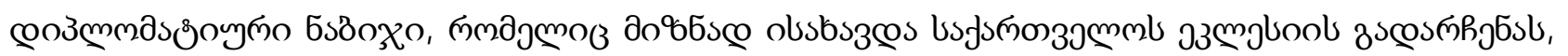

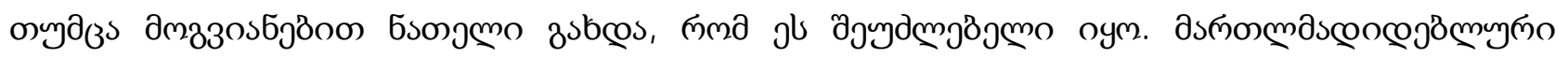

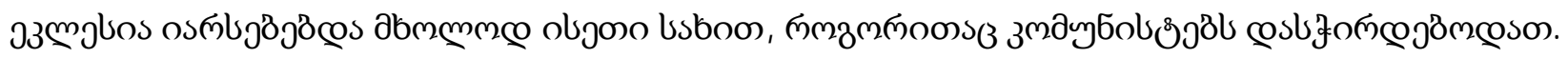

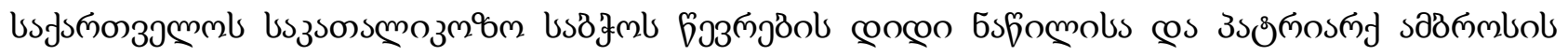

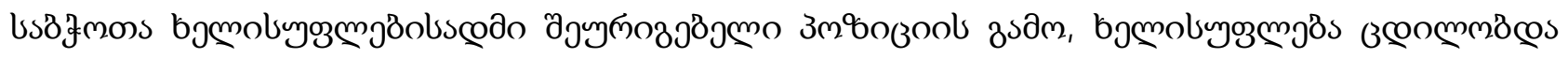

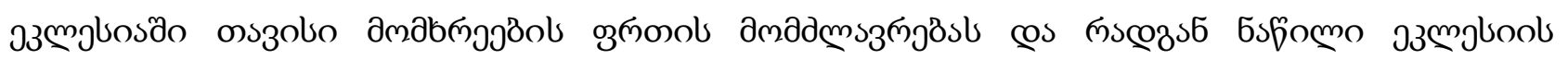

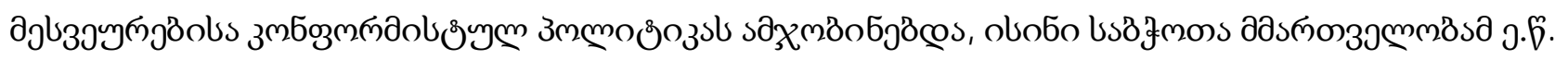

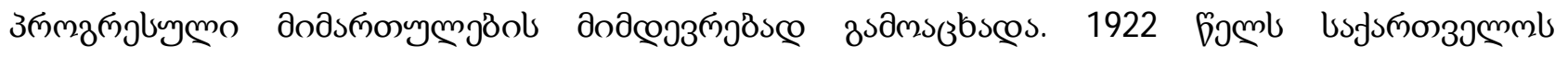

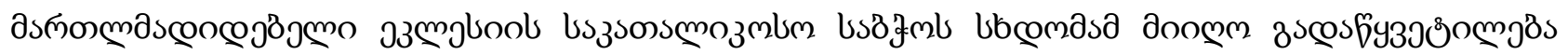

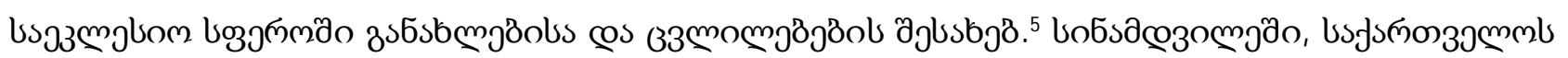

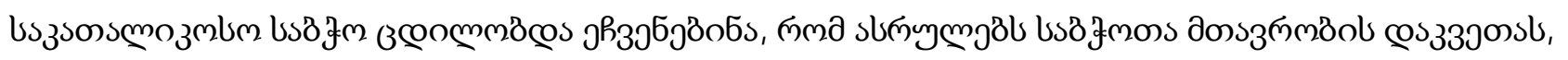




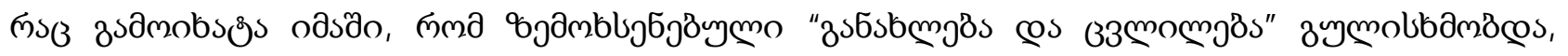

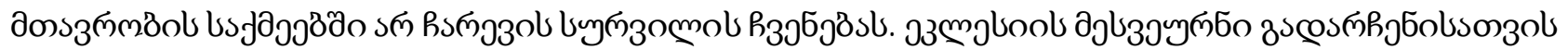

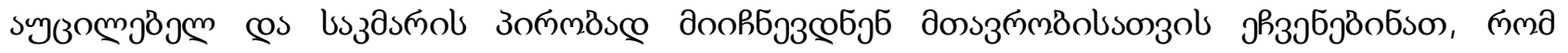

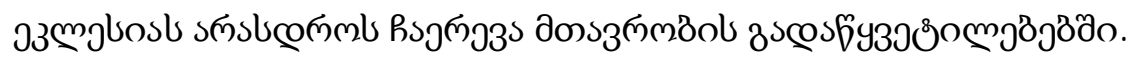

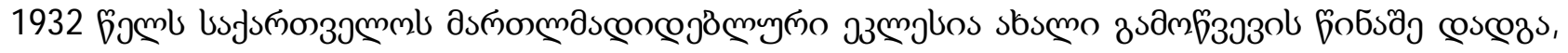

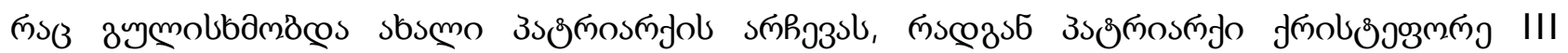

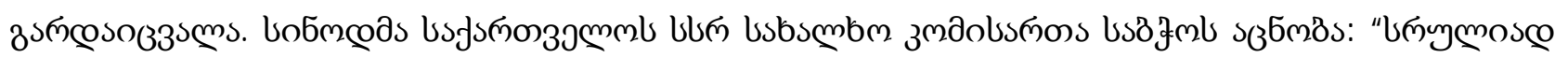

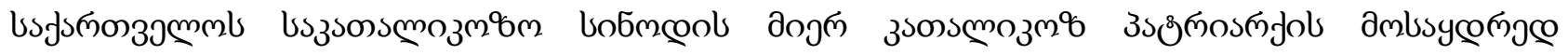

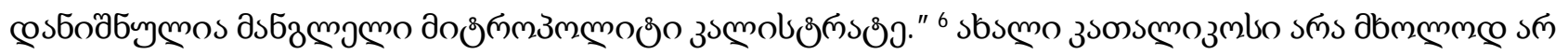

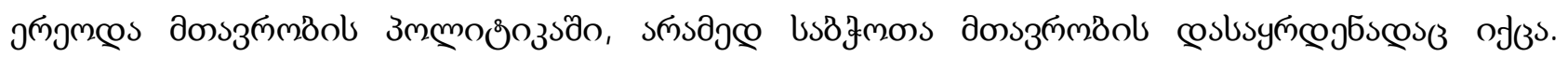

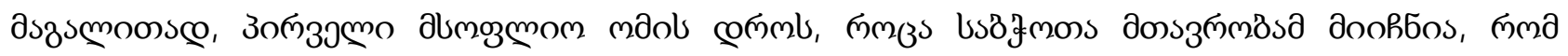

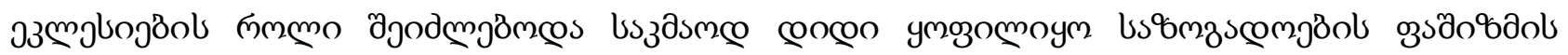

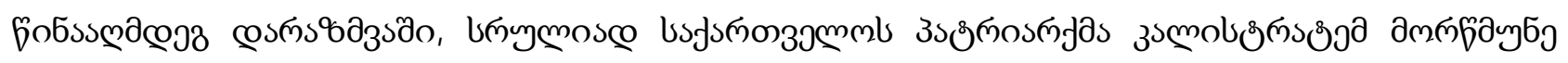

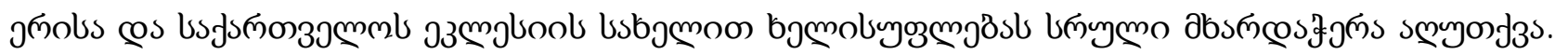

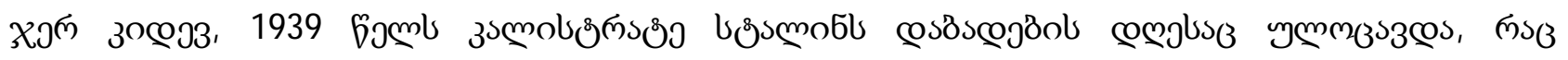

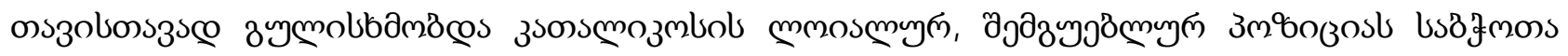

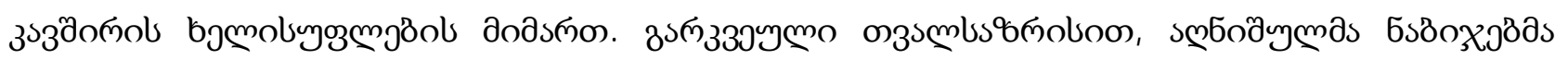

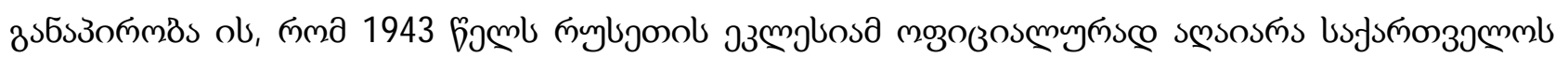

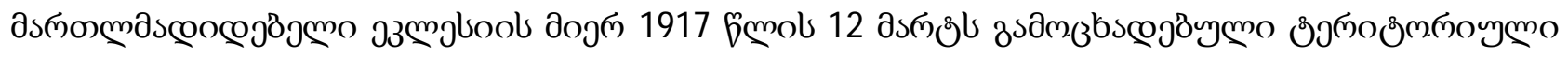

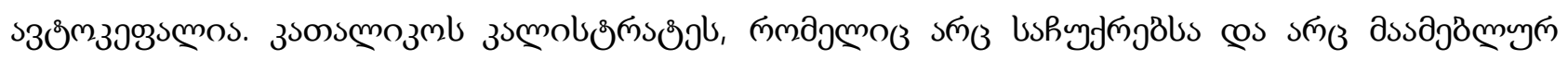

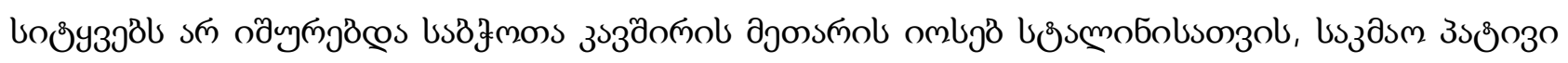

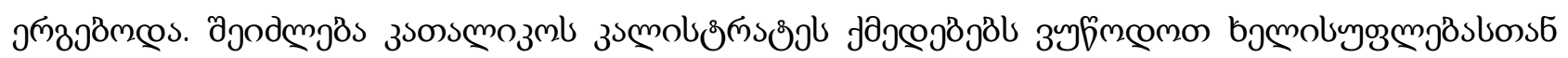

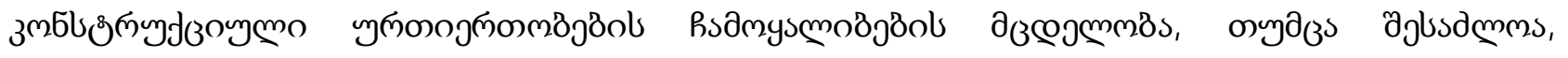

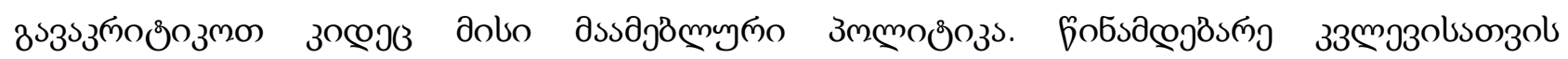

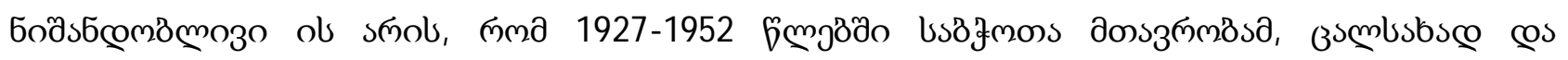

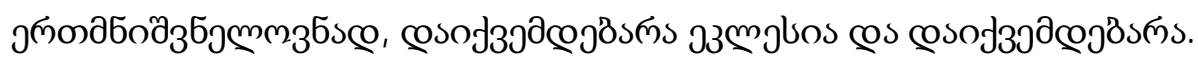

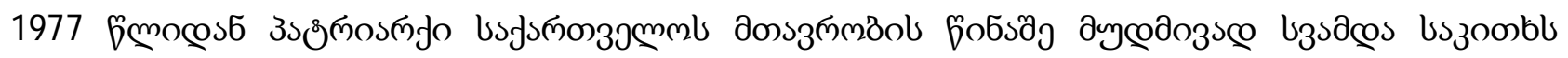

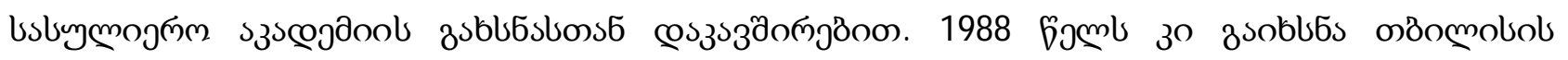

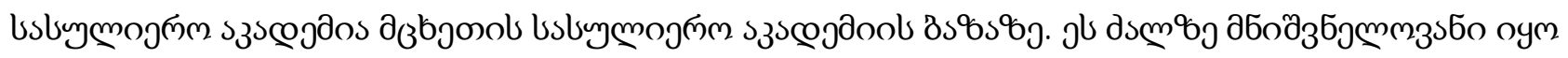

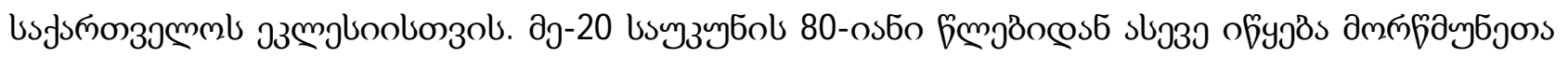

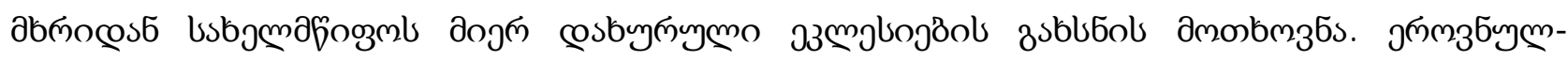

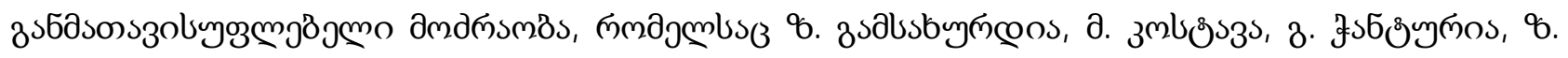

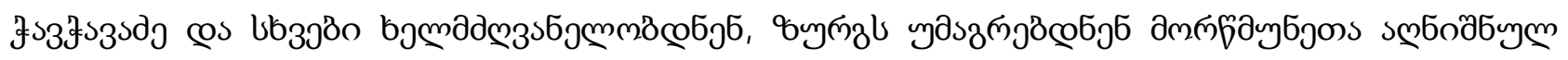

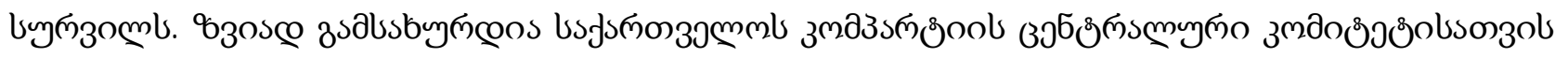

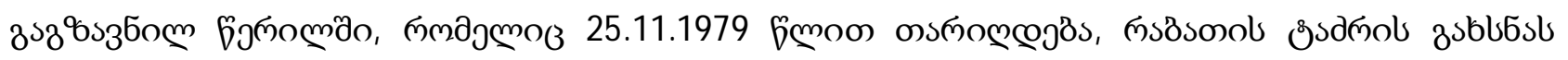

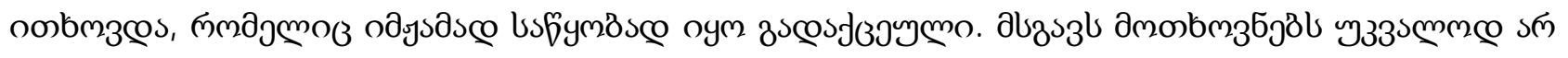

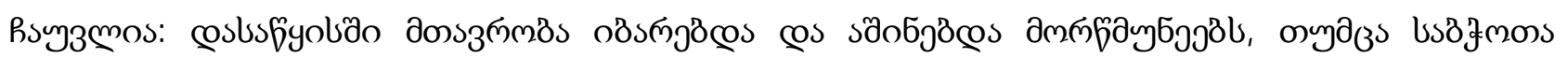

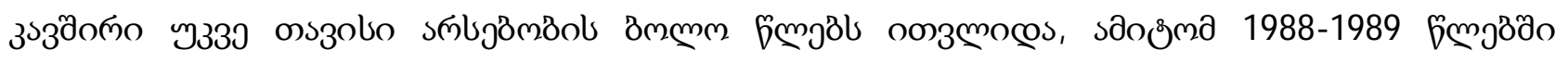




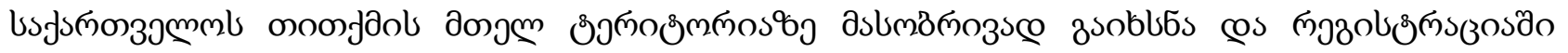

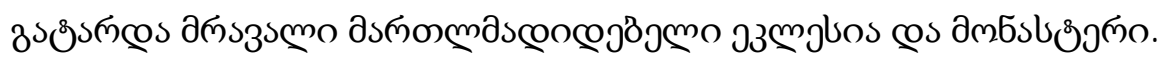

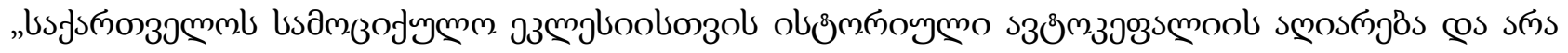

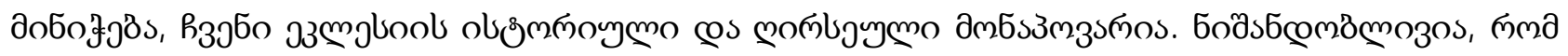

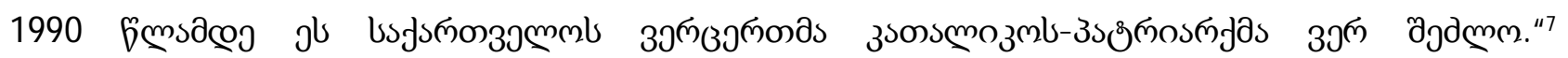

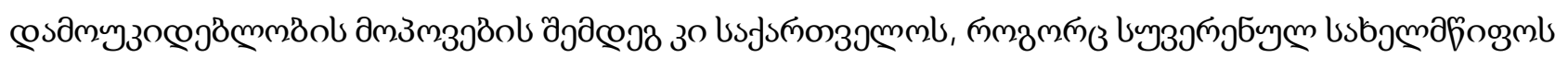

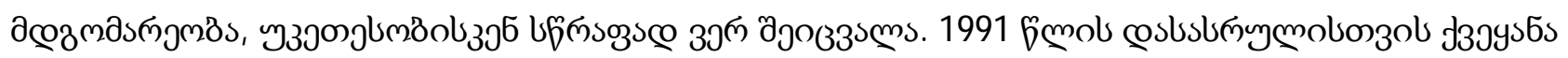

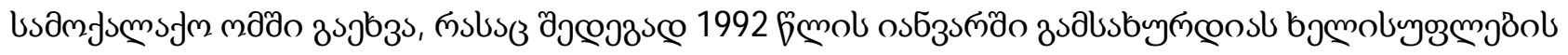

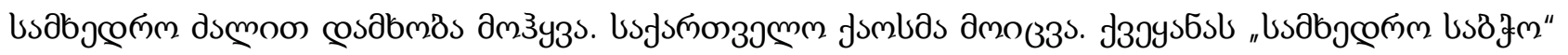

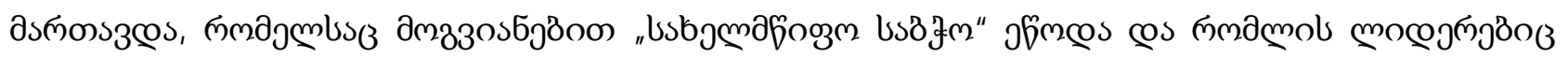

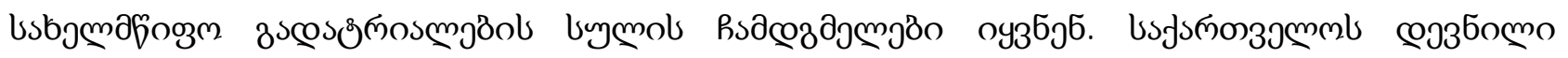

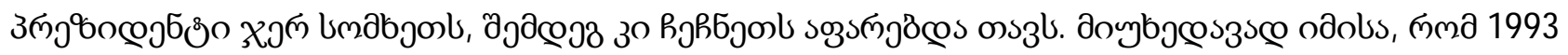

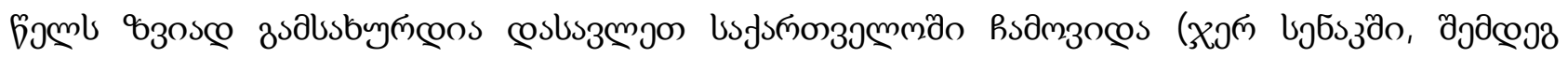

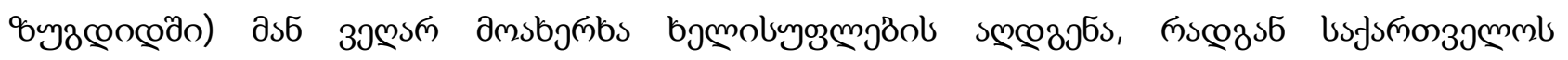

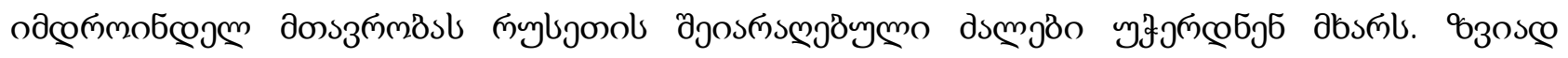

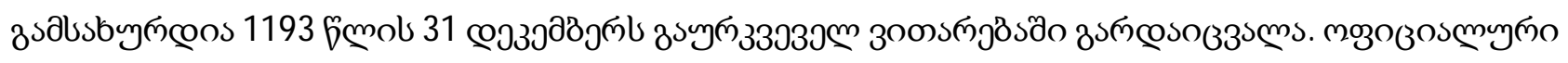

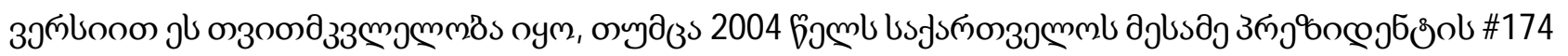

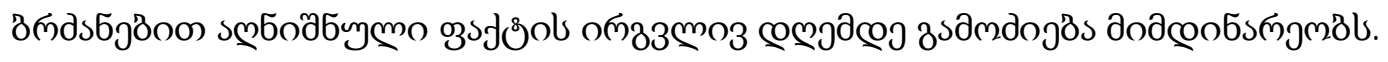

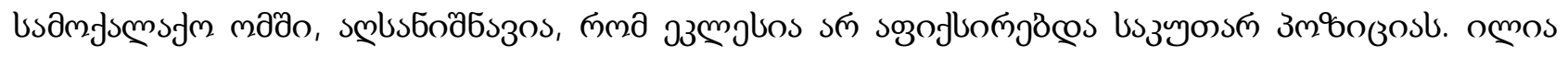

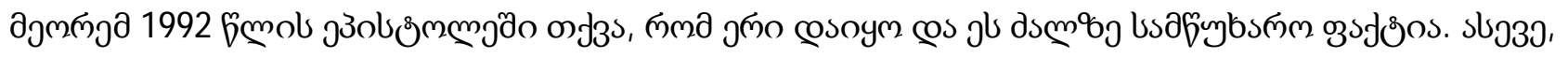

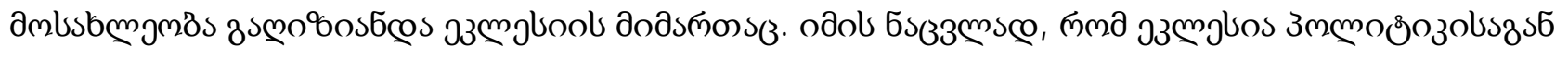

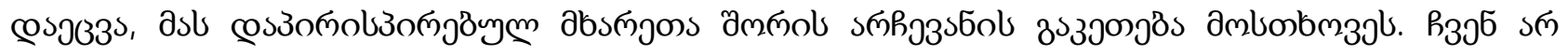

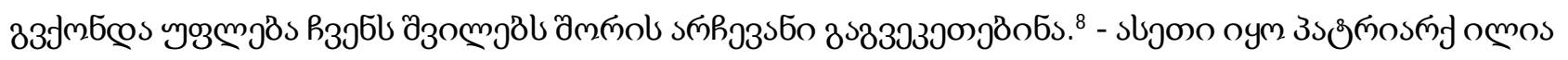
II-ob jろolsommgl zoбssmbo.

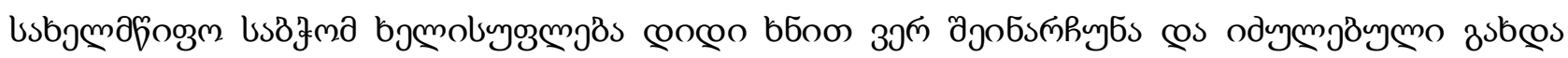

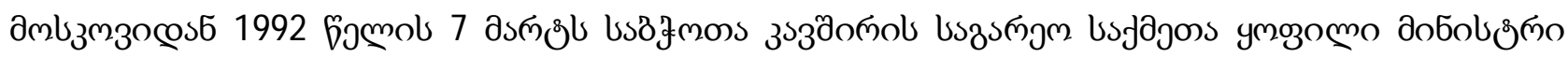

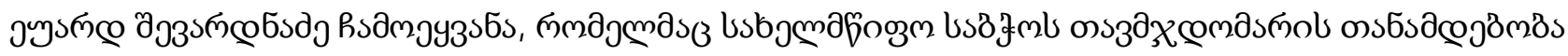

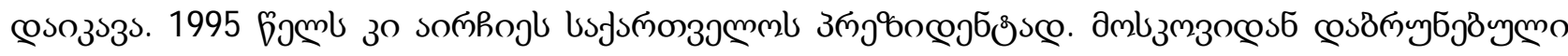

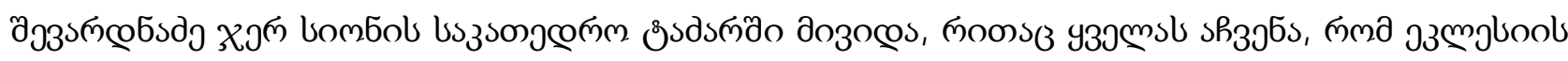

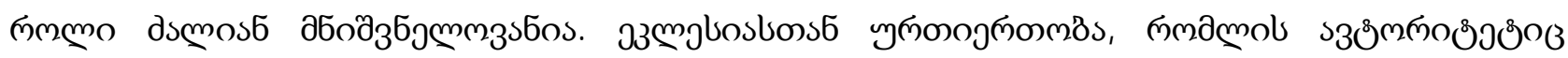

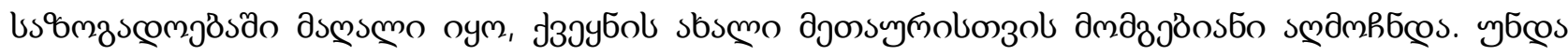

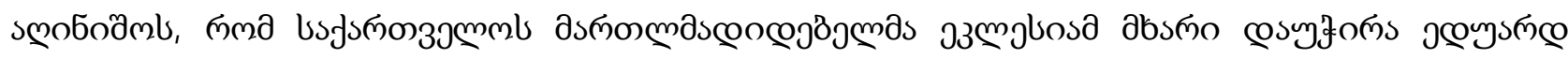

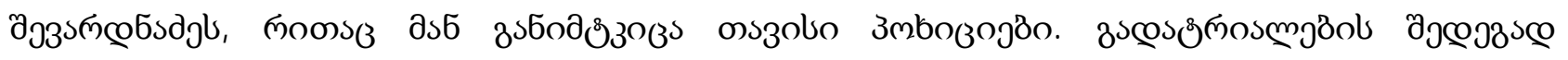

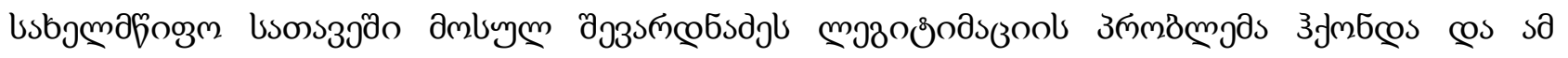

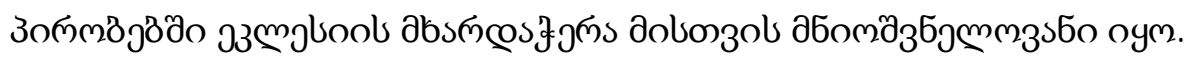

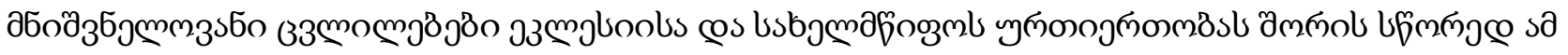

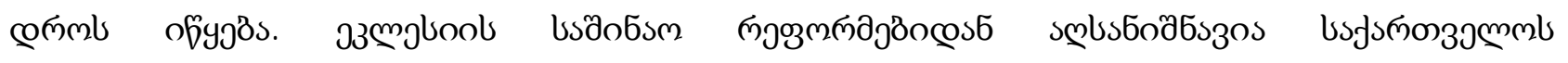

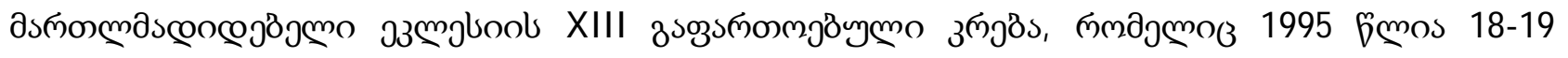




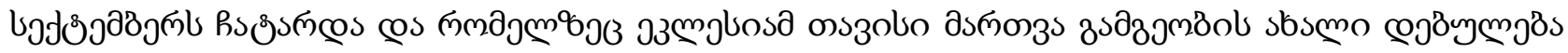
доомм. ${ }^{9}$

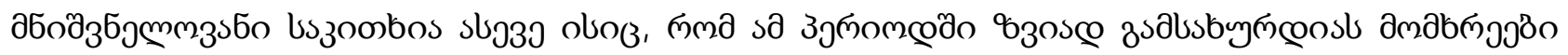

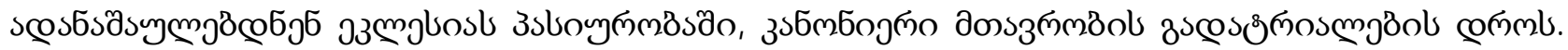

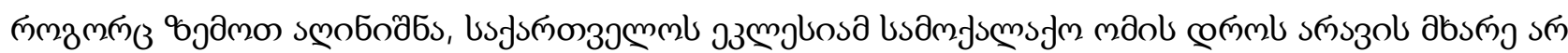

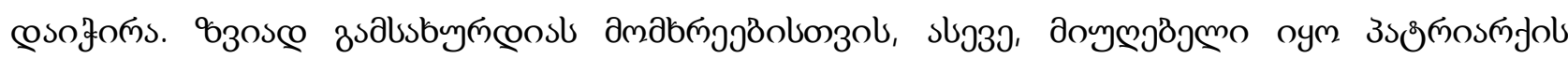

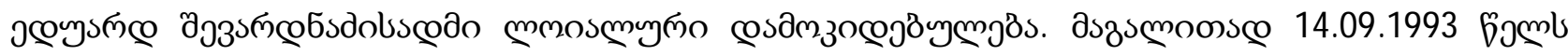

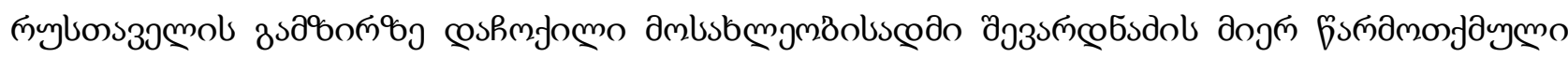

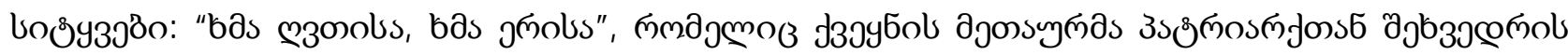

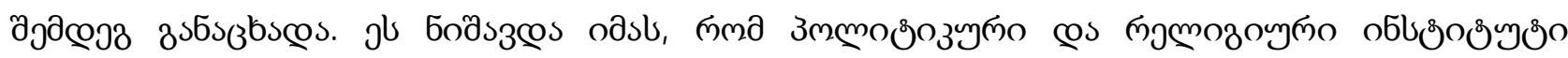

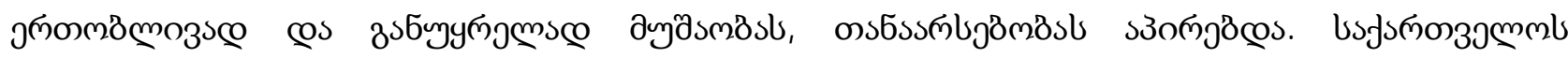

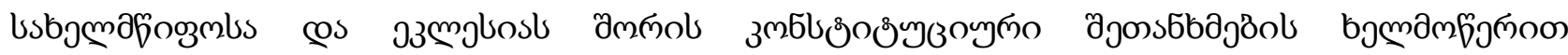

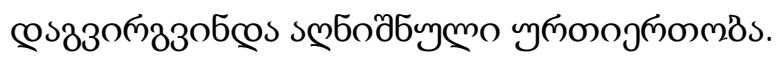

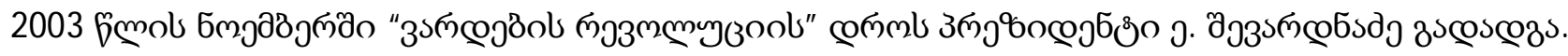

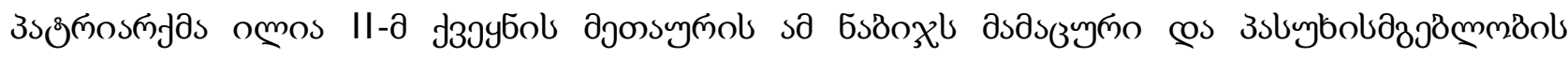

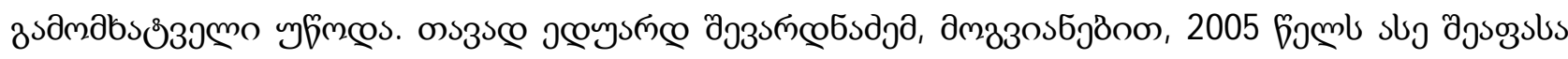

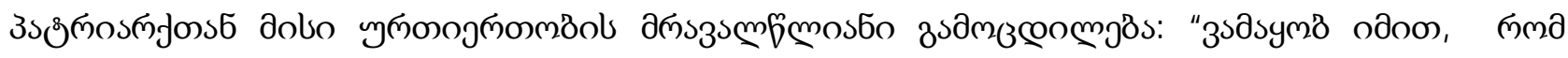

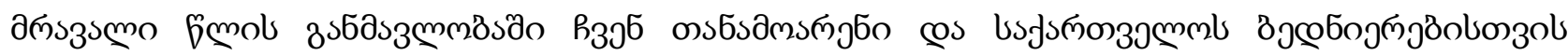

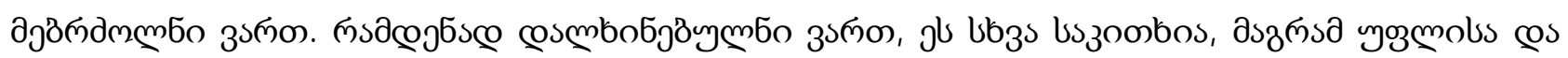

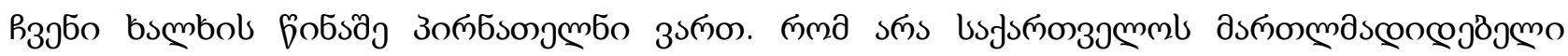

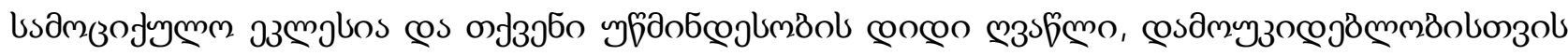

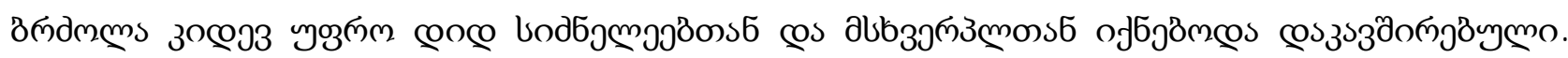

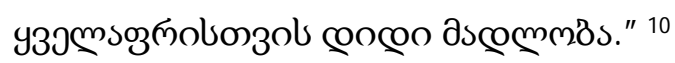

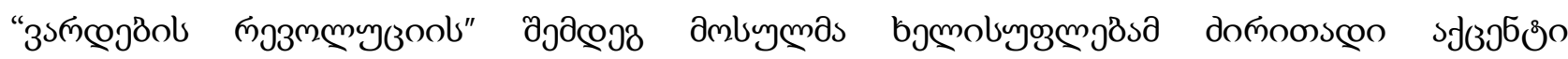

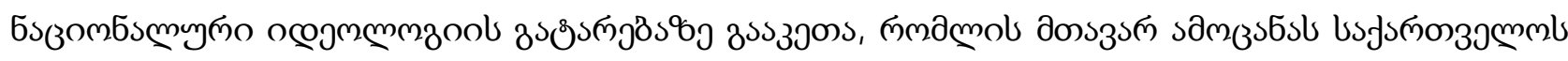

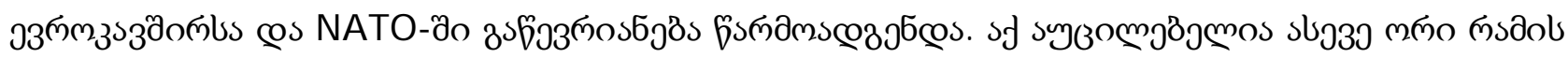
sмбoð3бs:

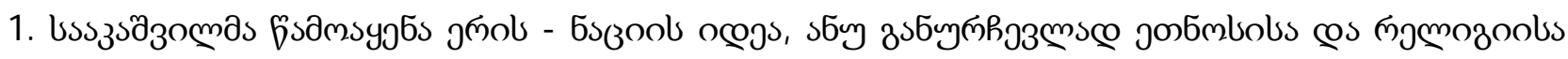

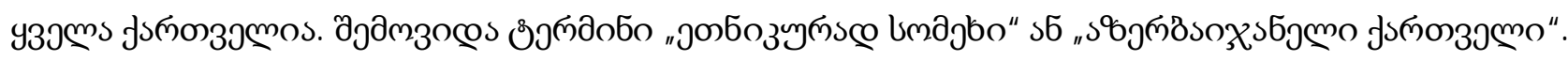

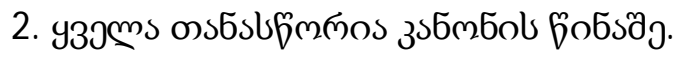

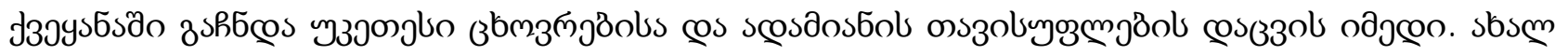

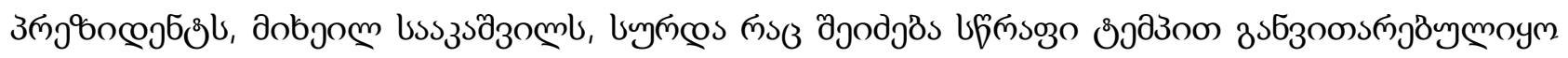

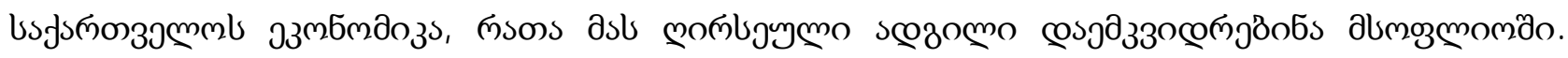

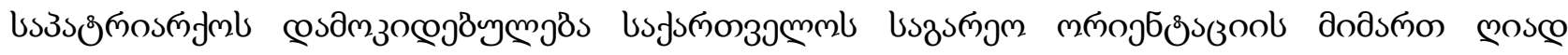

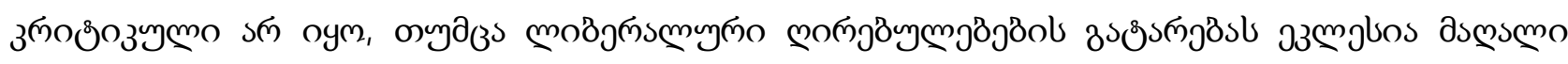

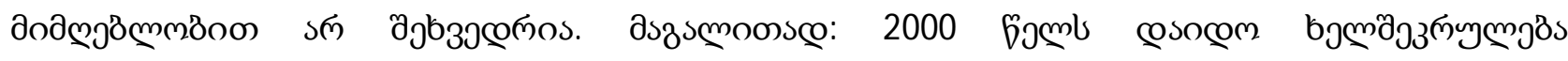

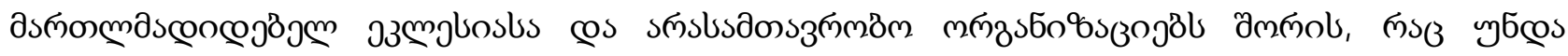




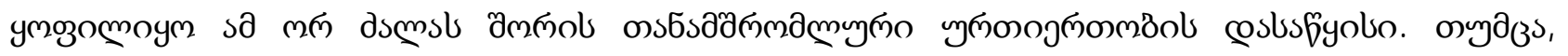

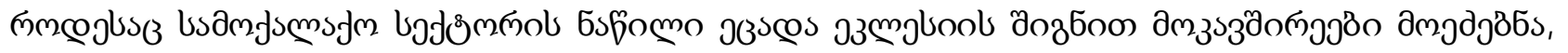

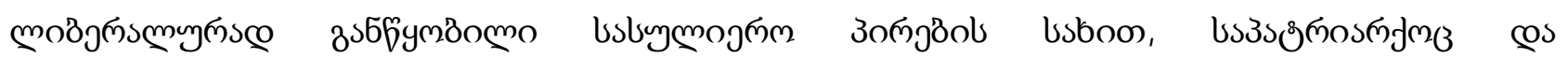

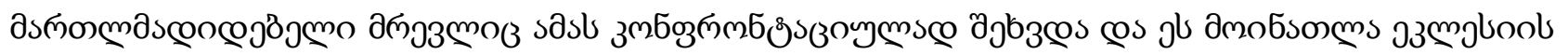

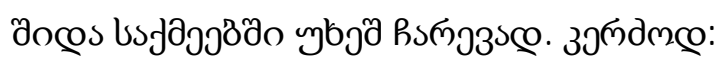

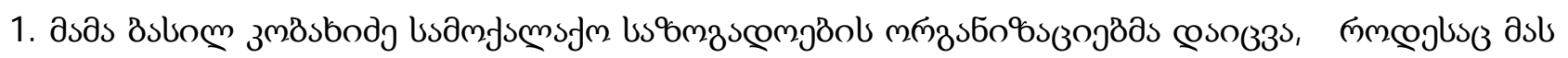

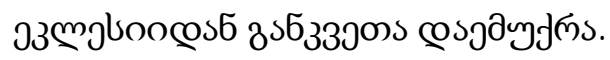

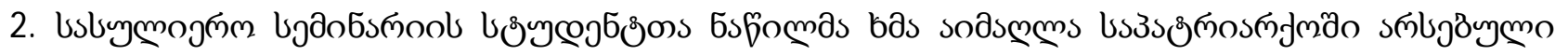

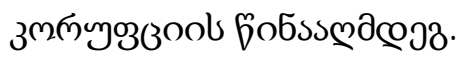

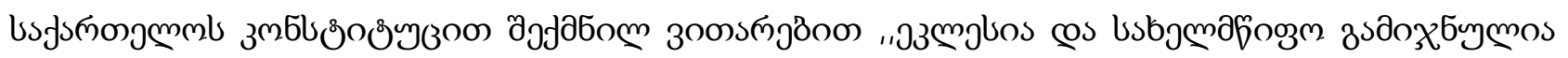

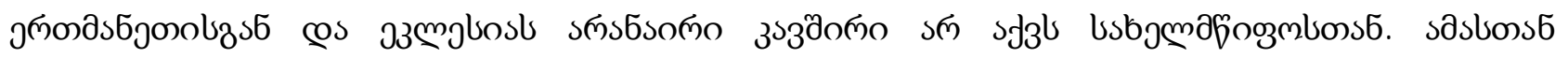

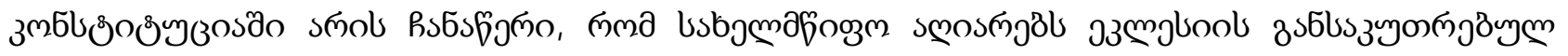

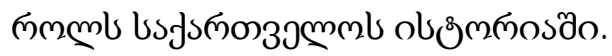

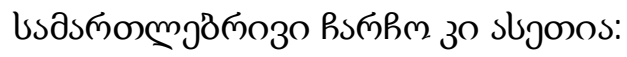

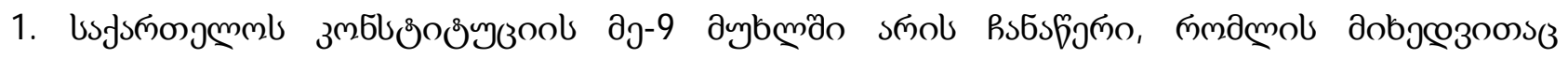

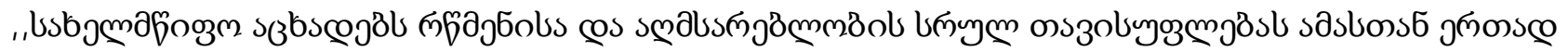

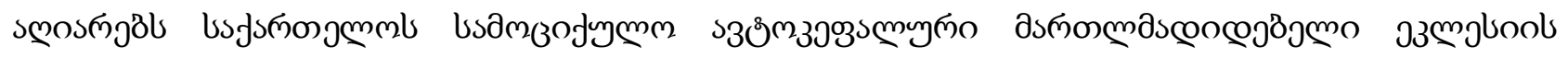

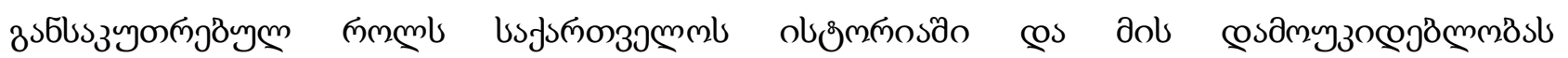
usbjmafogmuzs6".

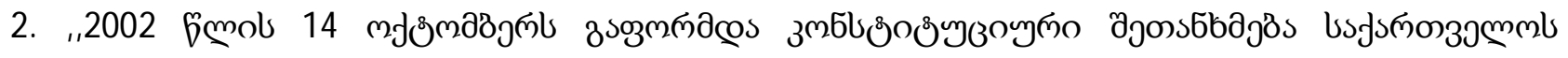

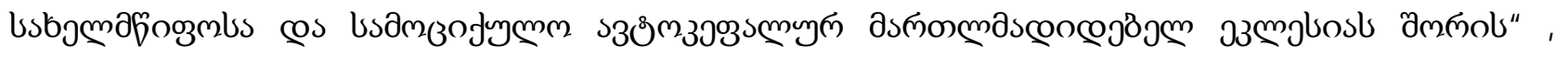

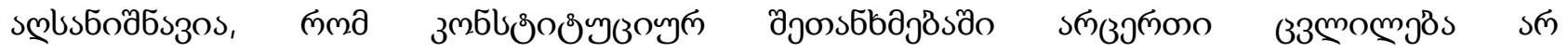

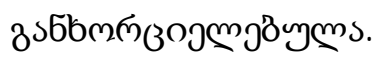

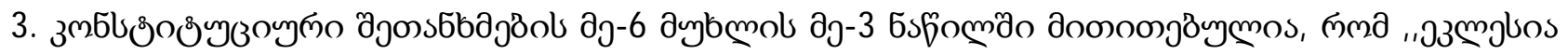

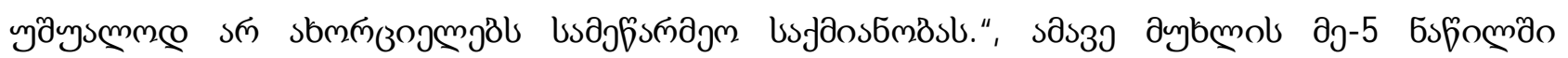

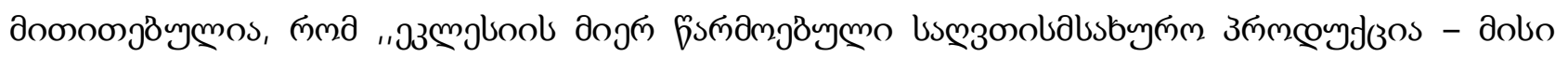

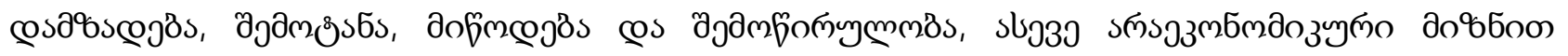

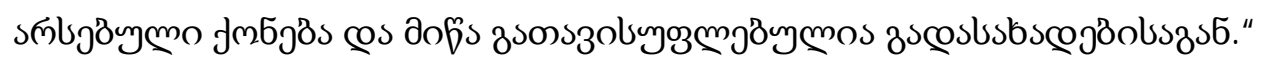

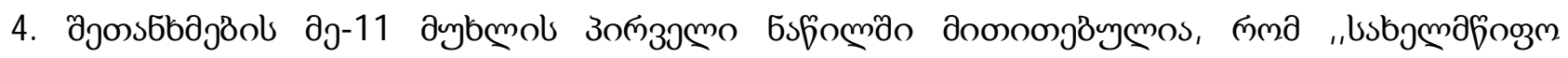

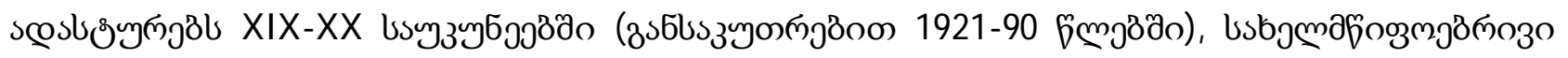

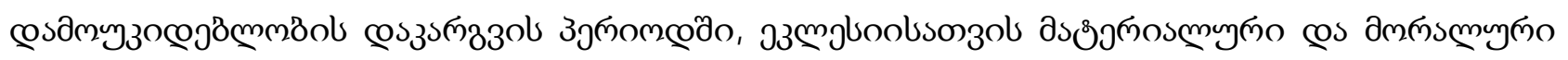

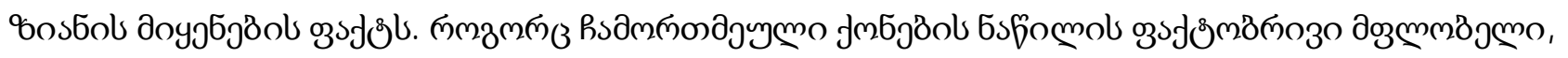

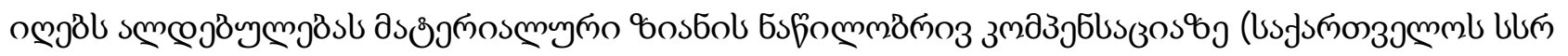

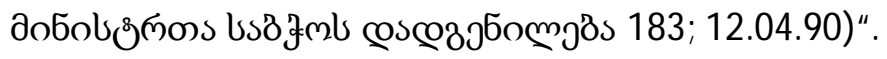




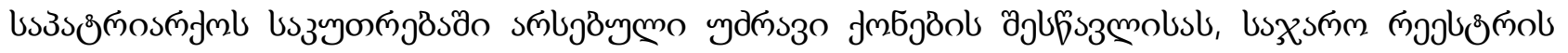

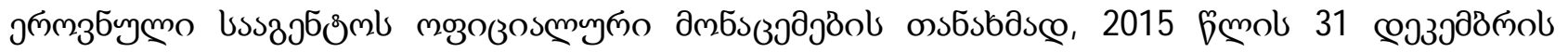

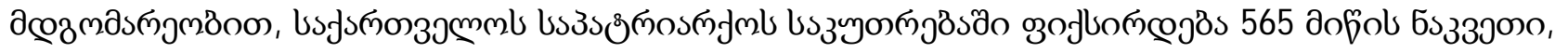

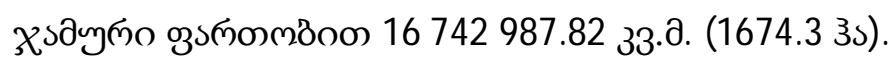

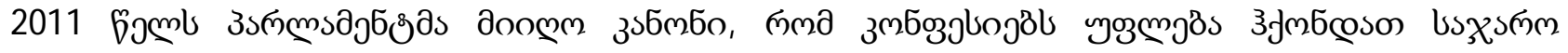

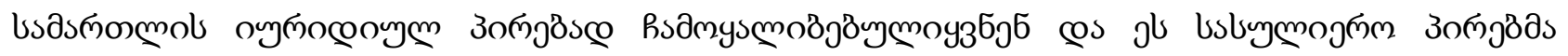

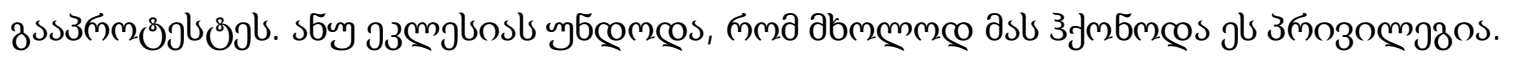

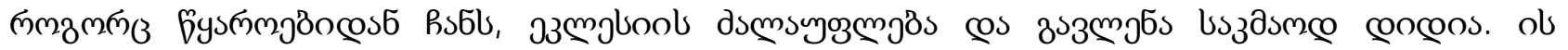

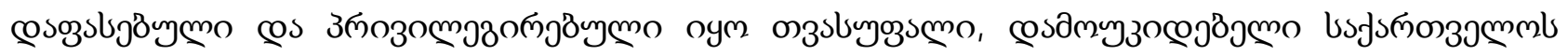

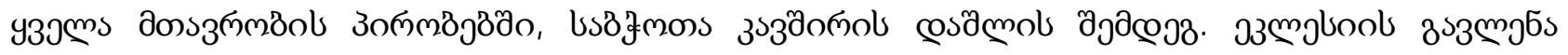

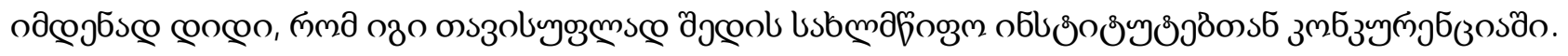

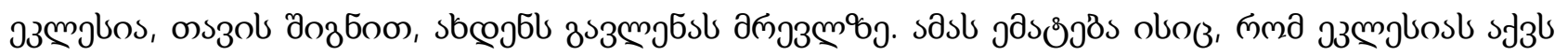

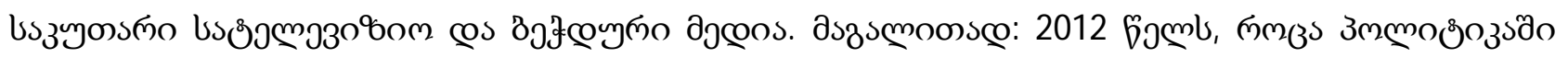

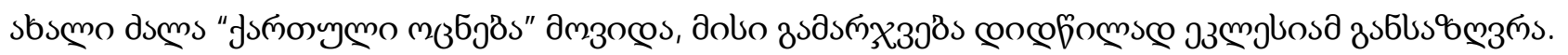

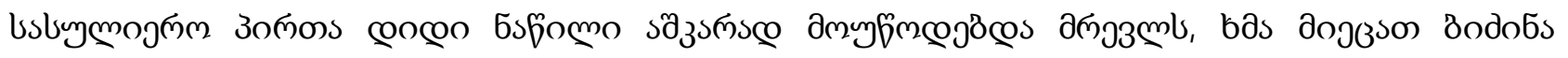
oзsбoбз

доэณ

əวЈӘбомо

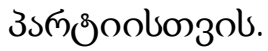

costs $33^{6 s}$

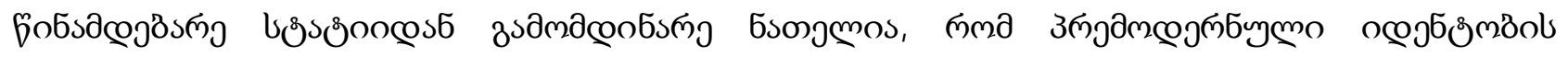

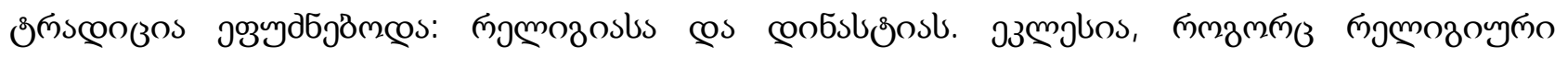

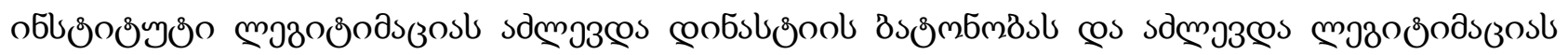

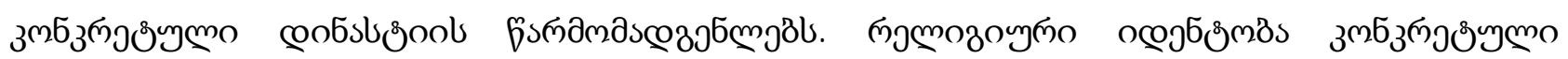

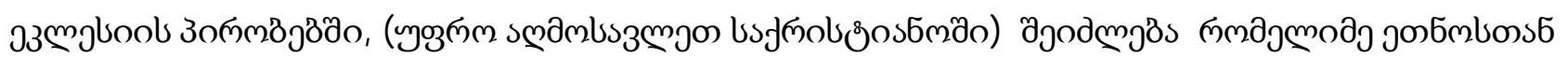

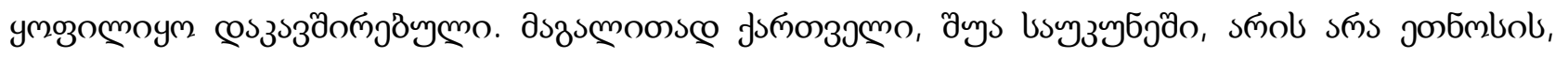

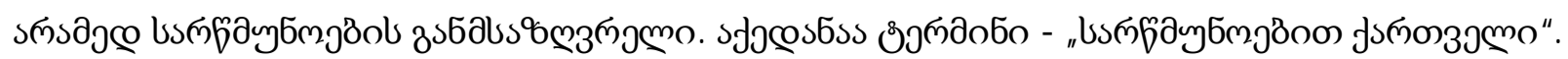

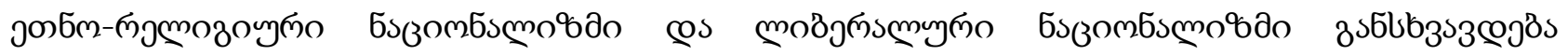

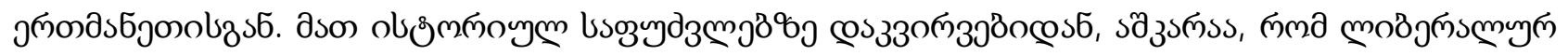

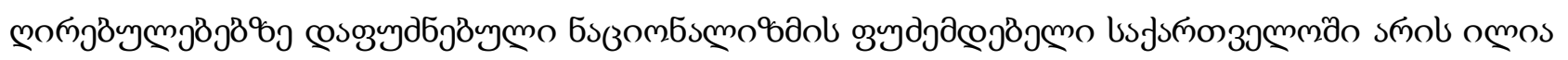

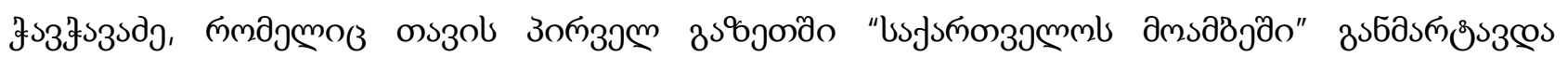

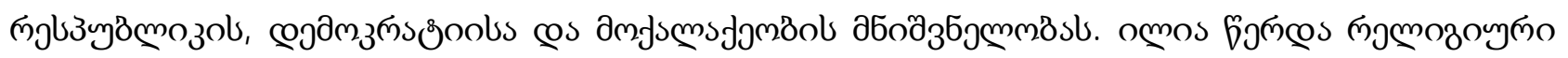

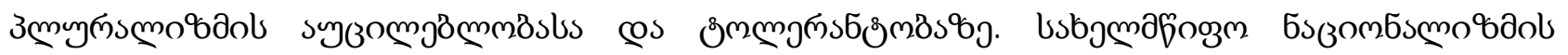

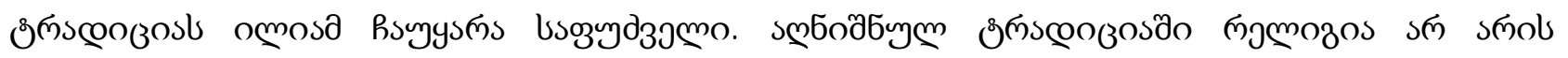

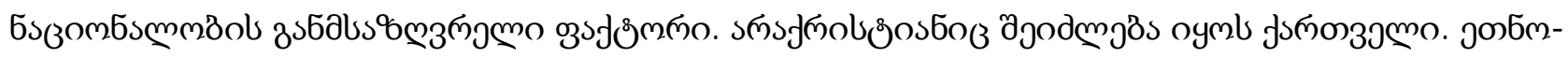

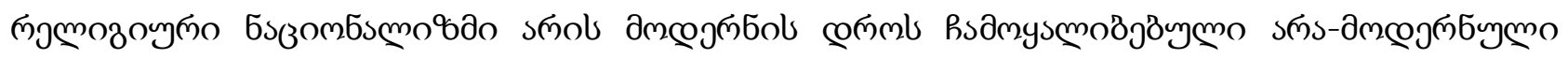

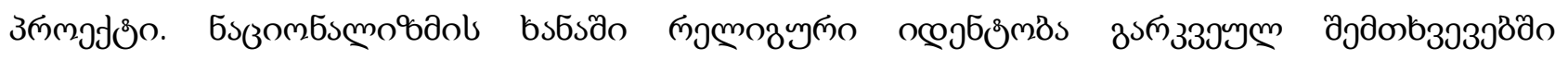

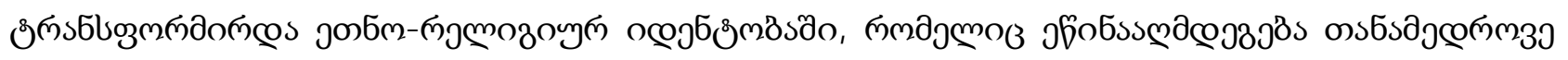




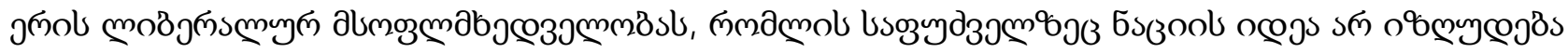

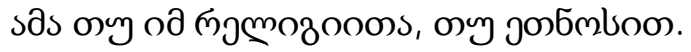

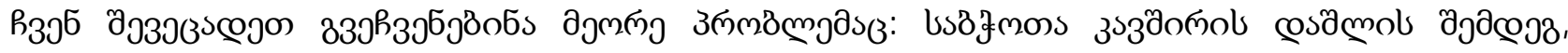

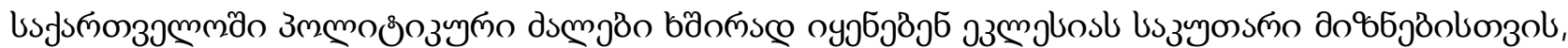

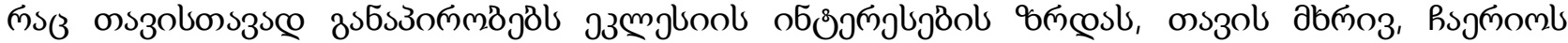

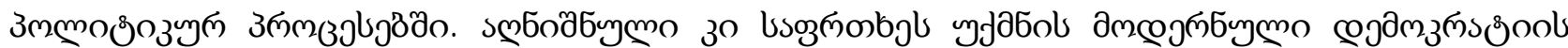

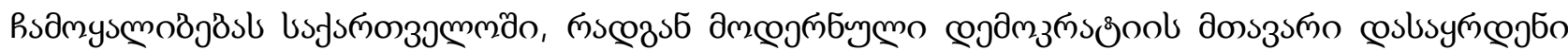

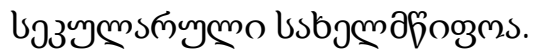

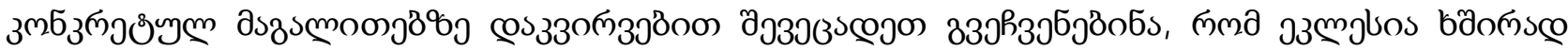

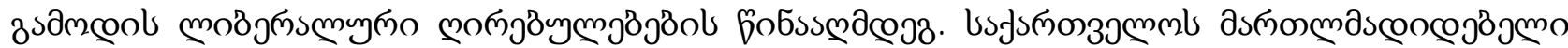

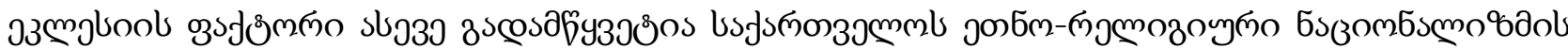

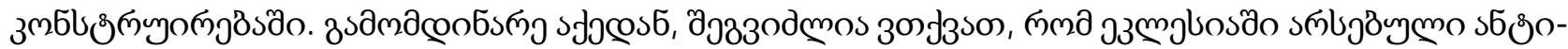

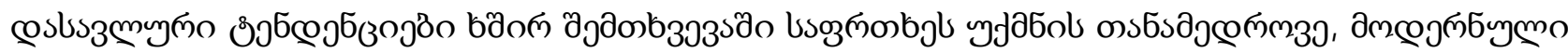

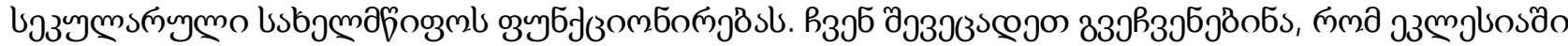

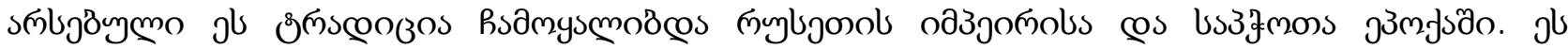

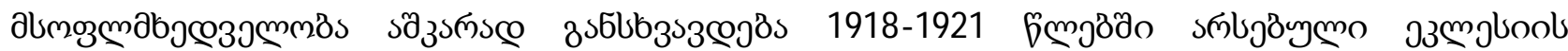

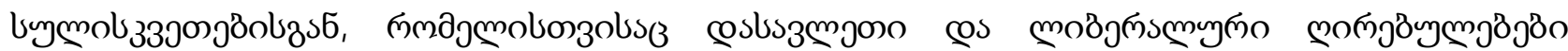

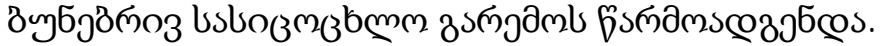

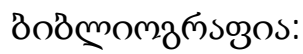

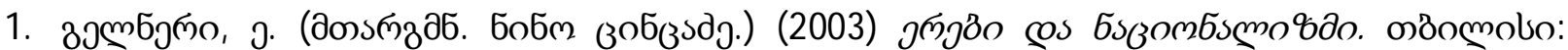
Бэзวณ์ .

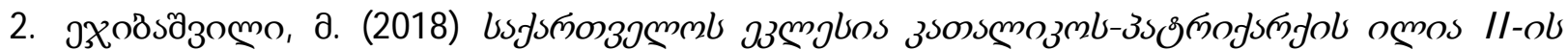

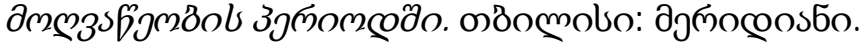

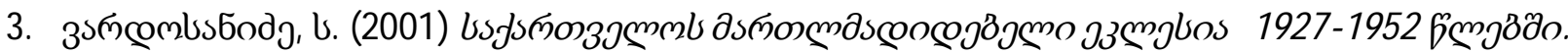

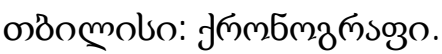

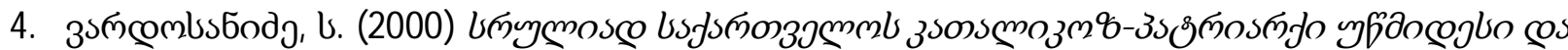

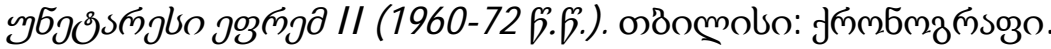

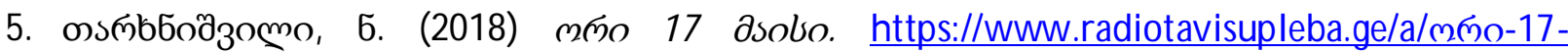
asolo/29228152.html (22.10.2020)

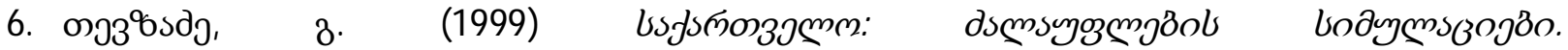
http://eprints.iliauni.edu.ge/25/1/1999\%20Simulations\%20of\%20Power.pdf (22.10.2020)

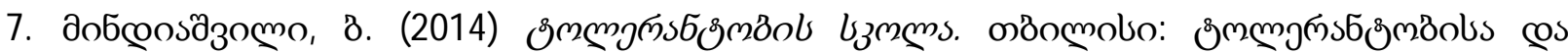

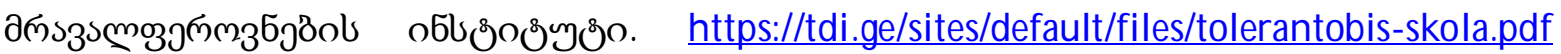
(23.10.2020)

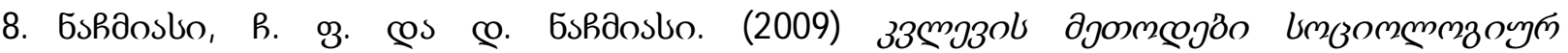

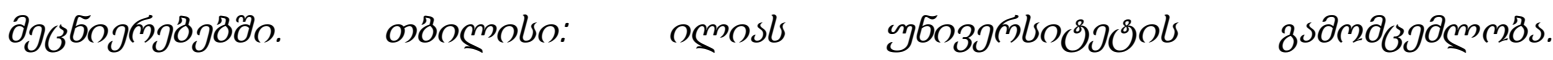


https://library.iliauni.edu.ge/wp-

content/uploads/2017/03/kvlevismetodebisociologiurmecnierebebshi.pdf (24.10.2020)

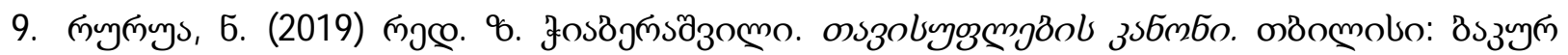

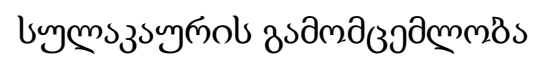

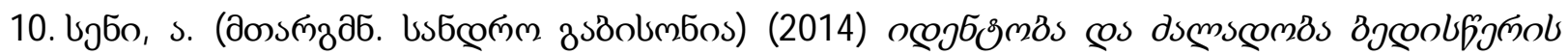

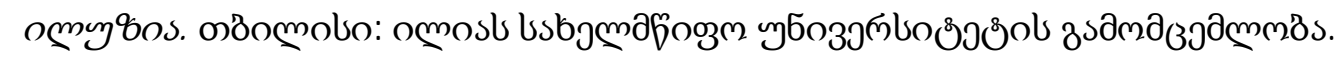

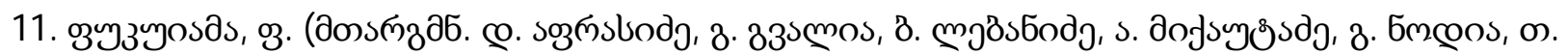

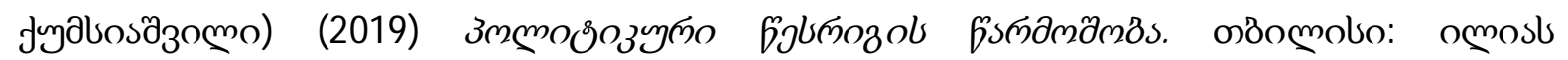

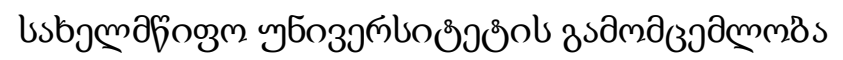

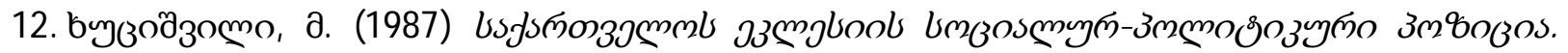

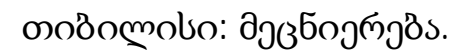

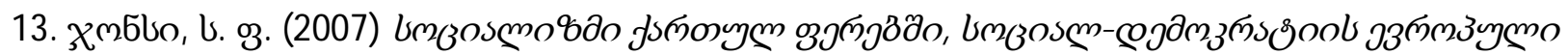

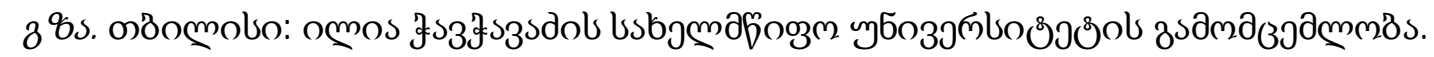

14. Diamond, L. J. (1996) Is the Third Wave Over? Journal of Democracy. Vol. 7. No. 3 (July)

15. Geremek, B. (1999) The Transformation of Central Eaurope. Journal of Democracy. Vol.10. No. 3 (July)

16. Huntington, S. P. (1997) After Twenty Years: The Future of the Third Wave. Journal of Democracy, Vol.8, No. 4, (october)

17. Lipset, S. M. (1998) George Washington and the Founding of Democracy. Journal of Democracy. Vol. 9. No. 4 (October)

18. Locke, J. (Trans. William, Popple) A Letter Concerning Toleration. https://socialsciences.mcmaster.ca/econ/ugcm/3113/locke/toleration.pdf (24.10.2020)

19. Soares, M. (1999) The Democratic Invention. Journal of Democracy. Vol. 10. No. 2 (April)

20. Shavtvaladze, M. (2018) The State and Ethnic Minorities: The Case of Georgia. Region

21. Vol. 7, No. 1 (January), pp. 43-68

https://ezproxy.iliauni.edu.ge:2111/stable/26537991?Search=yes\&resultttemClick=true\&searchTe xt=Georgian+religious+nationalism\&searchUri=\%2Faction\%2FdoBasicSearch\%3FQuery\%3DGe orgian\%2Breligious\%2Bnationalism\%26acc\%3Don\%26wc\%3Don\%26fc\%3Doff\%26group\%3Dno ne\&ab segments=0\%2Fbasic search solr cloud\%2Fcontrol\&refregid=fastlydefault\%3A1fd76708a8fef65236c54299eabc927b\&seq=1\#metadata info tab contents (22.10.2020) 


\title{
The Problem of Ethno-Religious Nationalism in Georgia
}

\section{Tinatin Kavtaradze}

\author{
PHD student in public administration, Georgian Institute of Public Affairs (GIPA), Faculty of Social \\ Sciences,
}

Ilia State University, Faculty of Arts, Lecturer in Social Sciences

https://orcid.org/0000-0003-3703-9294

\begin{abstract}
This research aims to demonstrate the range of Georgian Orthodox Church constructing the Georgian ethnoreligious nationalism. How ethnoreligious identity affects the functioning of a modern state? The pre-modern tradition of identity was based on religion and dynasty. Religious identity, under the church (mostly in eastern Christianity), could be associated with some ethnos. For example, Kartvelian", in the middle ages, is determiner not for ethnos but faith. From this derived the term - Kartvelian (Georgian) by faith.

Ethnoreligious nationalism and liberal nationalism are different. According to the tradition of state nationalism, religion is not a determinative factor for nationalism. Even non-Christian can be Georgian. The ethnoreligious nationalism is a non-modern project created during the modernity. In the period of nationalism religious identity, in some cases, was transformed into an ethnoreligious identity that contradicts a liberal understanding of the modern nation by which the idea of nation is not limited by religion or ethnos. Georgian Orthodox Church is an important factor forming Georgian ethnoreligious nationalism. Based on this, we can claim that the church's anti-western trends, often, hinder the functioning of the modern state. This trend was formed in the period of the Russian empire and the Soviet Union. This point of view is dramatically different from the 1918-1921 years' church's aspiration for which western and liberal values were natural and vital setting.
\end{abstract}

Keywords: Church, Secularism, State 